\title{
Different Orientation Tuning of Near- and Far-Surround Suppression in Macaque Primary Visual Cortex Mirrors Their Tuning in Human Perception
}

\author{
S. Shushruth, ${ }^{1 *}$ Lauri Nurminen, ${ }^{3 *}$ Maryam Bijanzadeh, ${ }^{1}$ Jennifer M. Ichida, ${ }^{2}$ Simo Vanni, ${ }^{3}$ and Alessandra Angelucci ${ }^{2}$ \\ ${ }^{1}$ Neuroscience Program and ${ }^{2}$ Department of Ophthalmology and Visual Science, Moran Eye Center, University of Utah, Salt Lake City, Utah 84132, and \\ ${ }^{3}$ Brain Research Unit, O.V. Lounasmaa Laboratory, Aalto University, FI-00076 Helsinki, Finland
}

\begin{abstract}
In primary visual cortex (V1), neuronal responses to stimuli inside the receptive field (RF) are usually suppressed by stimuli in the RF surround. This suppression is orientation specific. Similarly, in human vision surround stimuli can suppress perceived contrast of a central stimulus in an orientation-dependent manner. The surround consists of two regions likely generated by different circuits: a near-surround generated predominantly by geniculocortical and intra-V1 horizontal connections, and a far-surround generated exclusively by interareal feedback. Using stimuli confined to the near- or far-surround of V1 neurons, and similar stimuli in human psychophysics, we find that near-surround suppression is more sharply orientation tuned than far-surround suppression in both macaque V1 and human perception. These results point to a similarity between surround suppression in macaque V1 and human vision, and suggest that feedback circuits are less orientation biased than horizontal circuits. We find the sharpest tuning of near-surround suppression in V1 layers $(3,4 \mathrm{~B}, 4 \mathrm{C} \alpha)$ with patterned and orientation-specific horizontal connections. Sharpest tuning of far-surround suppression occurs in layer $4 \mathrm{~B}$, suggesting greater orientation specificity of feedback to this layer. Different orientation tuning of near- and far-surround suppression may reflect a statistical bias in natural images, whereby nearby edges have higher probability than distant edges of being co-oriented and belonging to the same contour. Surround suppression would, thus, increase the coding efficiency of frequently cooccurring contours and the saliency of less frequent ones. Such saliency increase can help detect small orientation differences in nearby edges (for contour completion), but large orientation differences in distant edges (for directing saccades/attention).
\end{abstract}

\section{Introduction}

In primary visual cortex (V1), neuronal responses to stimulation of the receptive field (RF) are modulated by simultaneous stimulation of the RF surround (Blakemore and Tobin, 1972; Maffei and Fiorentini, 1976; Nelson and Frost, 1978; Allman et al., 1985). In human vision, spatial context alters the perceived contrast of a central target stimulus (Ejima and Takahashi, 1985; Chubb et al., 1989; Cannon and Fullenkamp, 1991) and contrast sensitivity (Snowden and Hammett, 1998; Petrov et al., 2005). Surround stimulation usually suppresses the cell's spiking response to a high-contrast grating in its RF (DeAngelis et al., 1994; Levitt and Lund, 1997; Sengpiel et al., 1997; Walker et al., 2000).

Received May 22, 2012; revised 0ct. 22, 2012; accepted 0ct. 26, 2012.

Author contributions: S.S., L.N., S.V., and A.A. designed research; S.S., L.N., M.B., J.M.I., and A.A. performed research; S.S., L.N., and M.B. analyzed data; S.S., L.N., S.V., and A.A. wrote the paper.

We are grateful for support from the National Science Foundation (Grant IOS-0848106 to A.A.), the National Institute of Health (Grant EY015262 to A.A.), the Academy of Finland (Grants 124698, 218054, and 140726 to S.V.), the Finnish Graduate School of Neuroscience (to L.N.), the Academy of Finland National Programme for Centres of Excellence 2006-2011 (to L.N. and S.V.), and by a grant from Research to Prevent Blindness, Inc., to the Department of Ophthalmology, University of Utah. We thank Kesi Sainsbury for excellent histological assistance. We thank Dr. Sam Merlin for help with one experiment.

*S.S. and L.N. contributed equally to this work.

Correspondence should be addressed to Alessandra Angelucci, 65 Mario Capecchi Drive, Salt Lake City, UT 84132

E-mail: alessandra.angelucci@hsc.utah.edu.

S. Shushruth's present address: HHMI, University of Washington, Seattle, WA 98195.

DOI:10.1523/JNEUROSCI.2518-12.2013

Copyright $\odot 2013$ the authors $\quad 0270-6474 / 13 / 330106-14 \$ 15.00 / 0$
This suppression is orientation specific, typically being strongest when the stimuli in the RF and surround are of similar orientation, and weakest when they are of orthogonal orientation (DeAngelis et al., 1994; Sillito et al., 1995; Sengpiel et al., 1997; Walker et al., 1999; Cavanaugh et al., 2002), even when the stimulus in the RF is at a suboptimal orientation for the recorded cell (Shushruth et al., 2012). In human vision, the strength of surround effects is similarly orientation-dependent (Cannon and Fullenkamp, 1991; Solomon et al., 1993; Petrov et al., 2005).

We previously suggested that the surround consists of two regions, termed "near' and "far" (based on their proximity to the $\mathrm{RF}$ ), subserved by different anatomical circuits (Angelucci and Bressloff, 2006) (Fig. 1). Specifically, the large spatial extent (Levitt and Lund, 2002; Shushruth et al., 2009) and fast onset (Bair et al., 2003) of far-surround suppression in V1 suggest that this is generated by highly divergent (Angelucci et al., 2002) and fastconducting (Girard et al., 2001) feedback connections from extrastriate cortex. The small spatial extent (Angelucci et al., 2002) and slow conduction velocity (Grinvald et al., 1994; Bringuier et al., 1999; Girard et al., 2001) of intra-V1 horizontal axons, instead, suggest they contribute only to near-surround modulation. Surround suppression in the LGN (Sceniak et al., 2006; Alitto and Usrey, 2008) also contributes to near-surround suppression in V1 (Ozeki et al., 2004). In human vision, surround suppression shows similar spatial extent as in macaque V1 (Nurminen et al., 2009). 


\section{Extrastriate cortex}

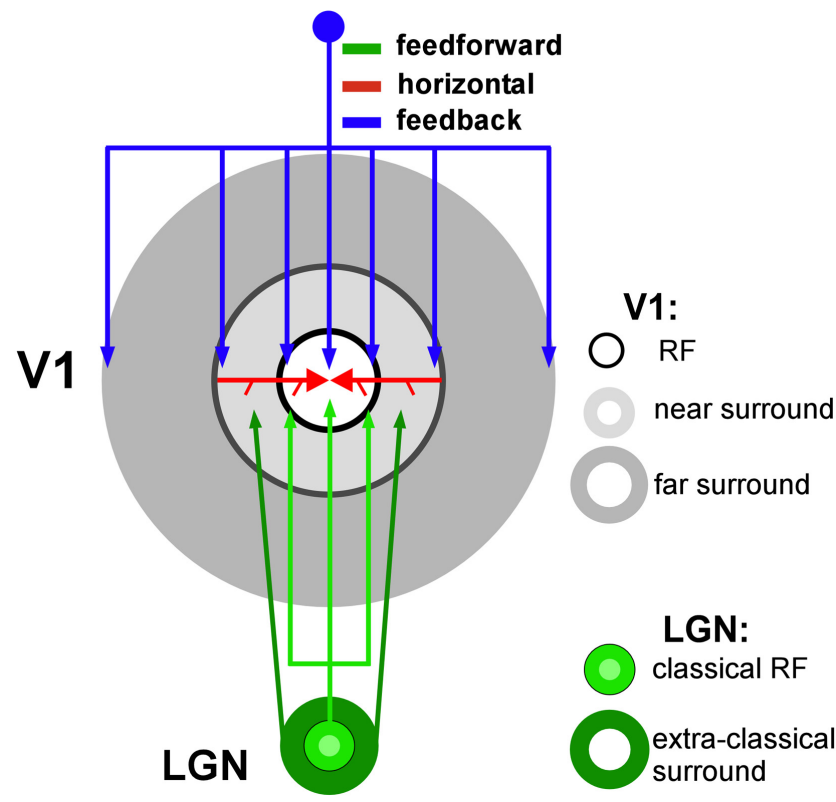

Figure 1. Presumptive anatomical circuits for surround modulation. Different components of the RF (white area) and surround (gray areas) of a 11 neuron, and their presumptive underlying circuits (arrows). Monosynaptic horizontal connections in V1 (red) extend into the near surround; their spread is commensurate with the size of a V1 neuron's spatial summation area measured at low contrast (Angelucci et al., 2002), which is on average about twice the diameter of the cell's RF, or spatial summation area measured at high contrast (Sceniak et al., 1999). The spread of feedforward connections to V1 from the LGN (Angelucci and Sainsbury, 2006) added to the size of suppressive surrounds of LGN cells (Sceniak et al., 2006; Alitto and Usrey, 2008) (dark green) is commensurate with a V1 cell's near surround. Interareal feedback connections (blue) are commensurate with the far surround (Angelucci et al., 2002) and contribute to all components of the RF and surround, but are the only connections contributing to the far surround.

Previous psychophysical and physiological studies of the orientation dependence of surround suppression have not distinguished between near- and far-surround stimulation. Thus, potential differences in the orientation tuning of these two regions are unknown. Here, using annular gratings confined to the near or far surround of macaque V1 neurons, and similar stimuli in human psychophysical experiments, we find that nearsurround suppression is more sharply orientation tuned than far-surround suppression in both macaque V1 and human perception. These results suggest different orientation specificities of the circuits underlying near- and far-surround suppression, and point to an important relationship between surround suppression in V1 and human perception. V1 laminar differences in surround orientation tuning further suggest laminar-specific connectivity. The different tuning of near- and far-surround suppression may reflect a statistical dependency in the joint distribution of oriented elements in natural images and may serve different perceptual roles.

\section{Materials and Methods}

\section{Electrophysiological recordings}

Extracellular recordings were made from parafoveal (range: $3-9^{\circ}$ eccentricity; mean: $5.7^{\circ}$ ) V1 of three (two males, one female) anesthetized (sufentanil citrate, $4-12 \mu \mathrm{g} / \mathrm{kg} / \mathrm{h}$ ) and paralyzed (vecuronium bromide, $0.1-0.3 \mu \mathrm{g} / \mathrm{kg} / \mathrm{h}$ ) macaque monkeys (Macaca fascicularis). All procedures conformed to the guidelines of the University of Utah Institutional Animal Care and Use Committee. The procedure of single-unit recording from V1 has been previously detailed (Shushruth et al., 2009). Briefly, animals were artificially respirated with a 30:70 mixture of $\mathrm{O}_{2}$ and $\mathrm{N}_{2} \mathrm{O}$, and vital signs were monitored continuously. The pupils were dilated with topical atropine, the corneas were protected with rigid gaspermeable contact lenses, and the eyes were refracted. The locations of the foveas were plotted at the beginning of the experiment and periodically thereafter, using a reversible ophthalmoscope.

Single-unit recordings were made with Epoxylite-coated tungsten microelectrodes (4-6 M $\Omega$; FHC). Spikes were conventionally amplified, bandpass filtered between $400 \mathrm{~Hz}$ and $5 \mathrm{kHz}$, and sampled at $22 \mathrm{kHz}$ by a dual-processor G5 Power Macintosh computer running custom software (EXPO, https://sites.google.com/a/nyu.edu/expo) courtesy of Dr. Peter Lennie. Spikes were displayed on a monitor, and templates for discriminating spikes were constructed by averaging multiple traces. The timing of waveforms that matched the templates was recorded with an accuracy of $0.1 \mathrm{~ms}$.

Visual stimuli. Sinusoidal gratings of the same mean luminance as the background were generated using the same software that recorded spikes and were displayed on a calibrated monitor (GDM-C520K, Sony) of mean luminance of $\sim 45.7 \mathrm{~cd} / \mathrm{m}^{2}$, resolution of $1024 \times 768$ pixels, refreshed at $100 \mathrm{~Hz}$, and placed at a viewing distance of $57 \mathrm{~cm}$. For each cell, recordings were made through the dominant eye, with the nondominant eye covered. We first determined the preferred orientation, drift direction, and spatial and temporal frequencies. Then the area and center of the minimum response field $(\mathrm{mRF})$ were carefully located quantitatively using a grating patch of $0.2^{\circ}$ diameter. The area of the mRF was defined as the visual field region in which the small grating patch elicited a response at least 2 SDs above the spontaneous rate, and the geometric center of this area was defined as the mRF center. We performed spatial summation measurements at $75 \%$ contrast using a circular drifting grating patch of increasing radius centered over the cell's mRF (e.g., Fig. $2 A$, black solid curve). The patch radius ranged from 0.1 to $13^{\circ}$ and consisted of 16 radii (in five steps of $0.1^{\circ}$ from 0.1 to $0.6^{\circ}$, and then $0.75,0.9,1,1.2,1.8,2.5,5$, $7.5,10$, and $\left.13^{\circ}\right)$. From these area summation functions for each cell, we extracted as a measure of RF size the patch radius at peak response (Fig. $2 A$, black arrow, corresponding to Fig. $2 B, C$, radius of the center grating patch). We then measured the cell response to an annular grating stimulus of $2^{\circ}$ thickness presented at varying distances from the RF, thus defined, in the absence of a central grating (Fig. $2 A$, purple curve). This procedure allowed us to determine the exact boundary of the RF excitatory zone (Fig. 2A, purple arrow, corresponding to Fig. 2B, purple circle, inner radius of the near-surround annulus), and to ascertain that surround stimuli presented alone outside this boundary did not evoke a spiking response from the cell.

The stimulus used to characterize the orientation tuning of near- and far-surround suppression consisted of a center circular grating patch matched to the RF diameter of the cell, surrounded by an annular grating presented in one of two possible configurations. In the near configuration (Fig. $2 B$ ), used to probe the near surround, the surround annular grating had an inner diameter of fixed size (purple circle), located $0.25^{\circ}$ outside the border of the neuron's RF or just outside the boundary of the excitatory zone, whichever was larger, and an outer diameter (blue circles) of two sizes, i.e., $4^{\circ}$ and $6^{\circ}$. In macaque, these diameters encompass the extent of most V1 neurons' horizontal connections (Angelucci et al., 2002) and the diameters of the suppressive surround fields for most LGN neurons (Sceniak et al., 2006; Alitto and Usrey, 2008). Therefore, this stimulus configuration maximized stimulation of the horizontal and feedforward connection-dominated near surround. In the far configuration (Fig. 2C), used to probe the far surround, the outer diameter of the surround annular grating was fixed in size and extended to the edge of the display $\left(26^{\circ}\right.$ ), while its inner diameter was of two sizes, i.e., $6^{\circ}$ and $4^{\circ}$ (Fig. $2 C$, blue circles); therefore, the surround stimulus activated spatially complementary regions to that of the near-surround stimulus. This stimulus configuration maximized stimulation of the far surround, presumably mediated by interareal feedback connections.

In both near- and far-surround configurations, the center and surround gratings were presented at the optimal spatial and temporal frequency for the neuron and at $75 \%$ contrast. The center grating (overlaying the RF) was always presented at the neuron's optimal orientation. The surround grating, instead, was presented at orientations 

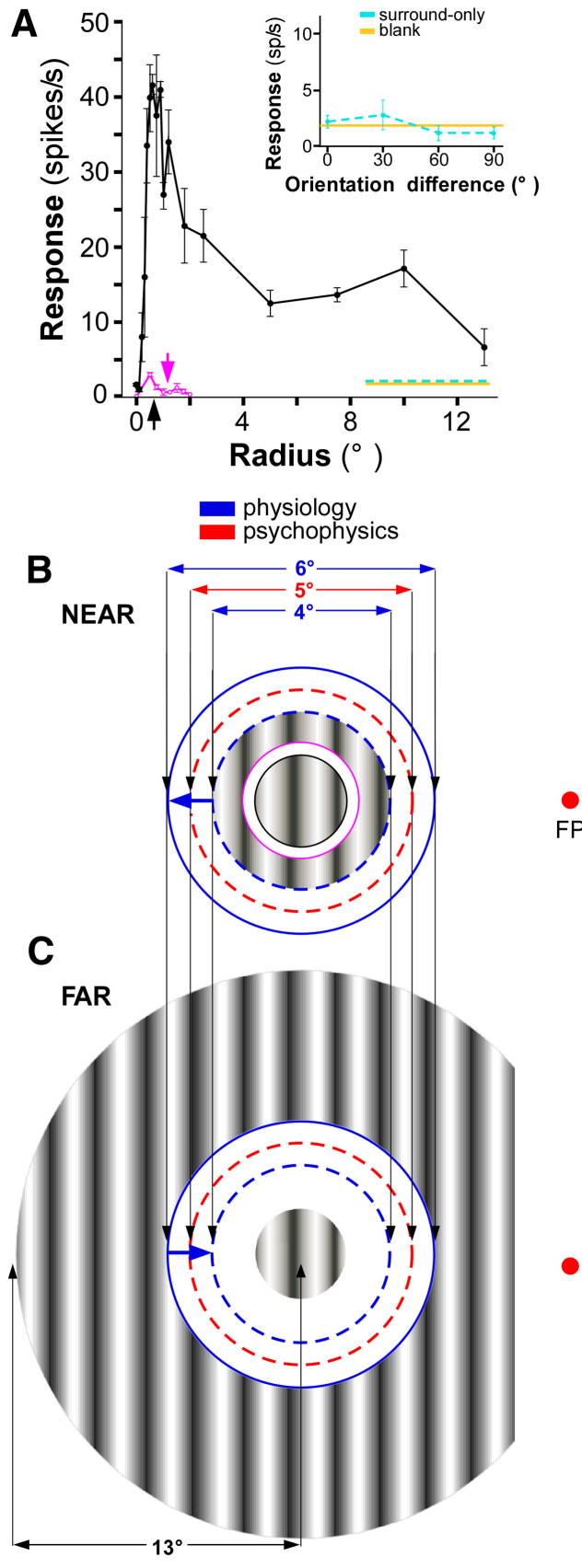

Figure 2. Visual stimuli used to characterize the orientation tuning of near- and farsurround suppression. $\boldsymbol{A}$, Area summation function for an example cell (same cell as in Fig. 5C). The black curve represents the cell response as a function of the radius of a grating patch centered on the mRF. The peak of this curve (marked by a black arrow) was taken to be the cell's $\mathrm{RF}$ radius and the center grating patch in $\boldsymbol{B}$ and $\boldsymbol{C}$ (marked by a solid black circle in $\boldsymbol{B}$ ) was set to be at this radius. The purple curve is the cell's response to an annular grating of $2^{\circ}$ thickness presented alone as a function of its inner radius. The purple arrow marks the outer boundary of the RF excitatory zone, and it was the smallest radius of this annulus at which there was no response from the cell. The inner radius of the near-surround grating in $\boldsymbol{B}$ (purple circle) was set to be at this value or $0.25^{\circ}$ outside the center grating, whichever was larger. Yellow line here and in the inset: spontaneous activity (i.e., response to the blank). Cyan line here and in the inset: response to a near $4^{\circ}$ surround grating alone (i.e., the grating marked by the dashed blue and purple circles in $\boldsymbol{B}$ ) at $0^{\circ}$ center-surround orientation difference (in the main panel) or as a function of orientation difference (in the inset). Note the lack of response to the near-surroundonly stimulus. $\boldsymbol{B}$, Near-surround configuration. For each recorded cell, the center grating was matched to the cell's RF diameter (black arrow in $A$ ), and the annular grating in the surround was presented with an outer diameter of $4^{\circ}$ and $6^{\circ}$ (blue circles). For psychophysics experiments, the center grating diameter was fixed at $2^{\circ}$, and the inner (purple circle) and outer (red circle) diameters of the surround grating were $3^{\circ}$ and $5^{\circ}$, respectively. Here and in the far ranging from optimal to orthogonal in $15^{\circ}$ steps (seven conditions). Each stimulus was presented for $700 \mathrm{~ms}$, with the first $200 \mathrm{~ms}$ consisting only of the center grating, and the surround grating appearing for the remaining $500 \mathrm{~ms}$. The relative phase of the center and surround gratings was randomized, but phase should not affect responses, because there was a gap between the center and surround gratings. This gap prevents brightness induction at the border between the center and surround gratings, thus rendering the surround suppression phase insensitive (Ejima and Takahashi, 1985; Petrov and McKee, 2006). The interstimulus interval was $1 \mathrm{~s}$. The delayed presentation enabled us to study the modulation of the steady-state response of the neuron, and to avoid ambiguities caused by the nonspecific response onset. The short presentation time also enabled us to examine these effects in a physiologically relevant time window, as the mean duration of fixations between saccades is $\sim 350 \mathrm{~ms}$ (Gallant et al., 1998). Each stimulus was presented for 10 trials, and the response to each condition was calculated as the average of the response to each trial during the last $500 \mathrm{~ms}$ of the stimulus. Because of the short stimulus duration, neurons with preferred temporal frequencies of $<2$ cycles/s whose responses were strongly modulated by the temporal frequency of the stimulus (F1/F0 ratio $>1)$ were not characterized with surround stimuli. Control conditions included a blank screen of the same luminance as the background for a measure of spontaneous activity (e.g., Fig. 2A, yellow line), a center-alone condition for a baseline response and surround annulus-alone conditions at all orientations and sizes, to ensure that the surround stimulus alone did not evoke a spiking response from the cell (e.g., Fig. 2A, dashed cyan line). A mask with the same luminance as the background was placed over the hemifield ipsilateral to the recorded hemisphere and extending $1.5^{\circ}$ beyond the vertical meridian into the contralateral hemifield, to prevent recruitment of callosal connections by the far-surround grating (Fig. 2C).

Data analysis. Spike trains were imported into Matlab and analyzed using custom scripts. The strength of surround suppression for each stimulus orientation was expressed as a suppression index (SI), which was calculated as

$$
S I(\theta)=1-\frac{R_{C S}}{R_{C}}
$$

where $\theta$ is the surround orientation for the condition, $R_{C}$ is the response to the center-only stimulus, and $R_{C S}$ is the response to the center plus surround stimulus. Thus, $\mathrm{SI}=0$ indicates complete lack of suppression, whereas SI $=1$ indicates that the cell's response was completely suppressed by the surround stimulus.

To characterize the orientation tuning of surround suppression, we used three complementary measures of orientation tuning: the circular variance (Cavanaugh et al., 2002; Ringach et al., 2002), the difference in suppression index $(\Delta \mathrm{SI})$, and the iso-orientation suppression fraction.

We calculated the circular variance $(\mathrm{CV})$ as a measure of the orientation selectivity of surround suppression for each cell as

$$
C V=\frac{\left|\sum_{n}\left(R_{\max }-R_{n}\right) \exp \left(i \theta_{n}\right)\right|}{\sum_{n}\left(R_{\max }-R_{n}\right)}
$$

where $R_{\max }$ is the maximal response of the cell (typically the response to the center-only stimulus at the optimal orientation for the cell), and $R_{n}$ is the response to the $n$th surround stimulus orientation. As we only presented seven surround orientations, $\theta_{n}$ was one of seven orientations

configuration the red dot indicates the location of the fixation point (FP) in the psychophysics experiment ( $6^{\circ}$ from the center of the stimulus). C, Far-surround configuration. The center grating was as in the near stimulus configuration. The surround grating had a $26^{\circ}$ (electrophysiology) or $24^{\circ}$ (psychophysics) outer diameter, and an inner diameter of two different sizes $\left(6^{\circ}\right.$ and $4^{\circ}$, blue circles) for the electrophysiology experiments, but of $5^{\circ}$ for the psychophysics experiments (red circle). The portion of the far-surround grating located between $1.5^{\circ}$ from the vertical meridian in the hemisphere ipsilateral to the location of the stimulus to the contralateral hemisphere was masked, to avoid activation of callosal connections. 
chosen to be equally spaced between 0 and $2 \pi$. This transformation projects the surround responses as vectors with equal angular separation along a circle, and hence, their normalized vector sum (CV) takes a value between 0 and 1 . A CV of 1 indicates that suppression is seen at only one surround orientation, whereas a CV of 0 indicates either equal suppression at all surround orientations or no suppression at any orientation. Thus, CV is a global measure of the shape of the tuning curve.

$\Delta$ SI was calculated as the difference between the mean SI for surround orientations close to optimal $(\theta$ to $\theta+15)$ and the mean SI for surround orientations close to orthogonal $(\theta+75$ to $\theta+90)$. This index is positive if the surround orientations close to optimal are more suppressive than the surround orientations close to orthogonal.

We defined iso-orientation suppression fraction for each cell as the area under the cell's suppression tuning curve between surround orientations of $0^{\circ}$ and $30^{\circ}$ as a fraction of the total area under the tuning curve (i.e., between surround orientations of $0^{\circ}$ and $90^{\circ}$ ). This was calculated from fitting the suppression index tuning curves with Gaussians of the form

$$
S I(\theta)=S I_{\min }+k e^{-(\theta / \alpha)^{2}}
$$

where $\mathrm{SI}_{\min }, k$, and $\alpha$ are the fitted parameters, and deriving the area under the fitted curves by numerical integration between the aforementioned surround orientation bounds. Thus, iso-orientation suppression fraction is a local measure of the sharpness of the tuning curve around its peak.

Statistical tests used to determine significance are reported in the Results, and, unless specified otherwise, the metrics reported are in terms of mean \pm SEM.

Histology and electrode track reconstruction. Electrolytic lesions $(1 \mu \mathrm{A}$ for 30-40 s, tip negative) were made along the length of the each penetration to assign laminar location to recorded cells. Our electrode penetrations were angled approximately orthogonal to the pial surface. At the end of the experiment, the animal was killed with sodium pentobarbital and perfused transcardially with saline, followed by $4 \%$ paraformaldehyde for 15-20 min. The brain was exposed by removing the top of the skull, the animal's head was repositioned in the stereotaxic apparatus, and the brain was blocked in a plane parallel to that of the electrode tracks. The blocked brain was removed from the rest of the skull, postfixed in the same fixative overnight and sectioned at $40 \mu \mathrm{m}$ parallel to the plane of blocking (i.e., a near-to-coronal plane). Alternate sections were stained for Nissl or cytochrome oxidase to reveal the V1 laminae. Electrode tracks were reconstructed by drawing lesions on each section using a camera lucida connected to a light microscope, and individual sections were aligned using vascular landmarks.

\section{Psychophysics}

Subjects. We report data from five subjects who participated in the current study. Subjects S1, S3, and S5 were naive to the purpose of the study. Subjects S2 and S4 were non-naive, and S2 was one of the authors of this study. Data from two additional inexperienced subjects was discarded because near-surround stimuli did not reliably suppress perceived contrast of the central stimulus. All subjects had normal or corrected-tonormal visual acuity.

Apparatus. The stimuli were displayed on a calibrated 22 inch Diamond Pro 2070 CRT monitor (NEC-Mitsubishi Electronics DisplayEurope) via a Visage system (Cambridge Research Systems) that provides 14-bit grayscale resolution. The resolution of the monitor was $800 \times 600$ pixels $(39.0 \times 29.2 \mathrm{~cm})$ at a $100 \mathrm{~Hz}$ refresh rate. The binocular viewing distance was stabilized to $68 \mathrm{~cm}$ with a chin rest.

Procedure. We used a contrast matching task, because this relates to the mean of the underlying response distribution better than contrast detection or discrimination paradigms (as discussed in Chen and Tyler, 2002). Such comparison assumes that neuronal firing rate is monotonically related to perceived contrast. However, differences between the psychophysical and electrophysiological approach, as well as possible interspecies differences, only allow for qualitative comparison between psychophysical and electrophysiological results.

Each trial began with a $300 \mathrm{~ms}$ presentation of the fixation point. After the initial fixation period, the fixation point disappeared for $100 \mathrm{~ms}$.
Then the fixation point appeared again simultaneously with either the test or the comparison stimulus. The test stimulus consisted of a center and a surround grating, while the comparison stimulus consisted of only the center grating. The temporal order of the test and the comparison stimulus were randomized. The stimulus duration was $300 \mathrm{~ms}$, and the interstimulus interval was $1000 \mathrm{~ms}$. At the end of a trial, the subjects indicated with a keyboard button press the interval in which the contrast of the center grating appeared higher. The subject's answer initiated the next trial. We measured the perceived contrast of the center grating using a two-interval staircase procedure. Specifically, if the subject indicated that the contrast of the comparison stimulus appeared higher than the contrast of the test stimulus, the contrast of the comparison stimulus was decreased. Likewise, if the comparison stimulus appeared to have lower contrast, its contrast was increased. There were two independently progressing staircases. A reversal point was defined as the contrast at which the direction of the staircase changed. The perceived contrast of the test center grating was defined as the mean of the last four reversal points of both staircases. The first two reversals were disregarded as practice.

Visual stimuli. Stimuli were similar to those used for the electrophysiological experiments. The test stimulus consisted of a center sinusoidal grating patch surrounded by an annular grating (Fig. $2 B, C$ ). The test center grating was always displayed at horizontal orientation. The orientation of the surround grating was varied from collinear to orthogonal (relative to the center) in $15^{\circ}$ intervals. The Michelson contrast of the center grating was $20 \%$, and that of the surround was $40 \%$. These contrasts were selected to avoid saturation of V1 population contrast responses. The $20 \%$ contrast used here is above semi-saturation for approximately half of V1 cells (Albrecht and Hamilton, 1982). This contrast value is lower than that used for the physiology experiments. However, we expect this to have minor effects on the orientation tuning of surround suppression in contrast matching, because, at least in V1, the effect of contrast on the orientation tuning of suppression is small $(\mathrm{Ca}-$ vanaugh et al., 2002): it affects $\sim 50 \%$ of cells and is not necessarily consistent across the cell population (Levitt and Lund, 1997). The spatial frequency of the center and surround gratings was 1 cycle per degree, relative spatial phase was fixed, and in phase the diameter of the center grating was $2^{\circ}$, and the stimuli were centered at $6^{\circ}$ eccentricity. This eccentricity corresponds approximately to the mean of the distribution of eccentricities for the V1 cell population. In the near-surround configuration, the inner diameter of the surround annulus was $3^{\circ}$ (Fig. $2 B$, purple circle) and its outer diameter was $5^{\circ}$ (Fig. $2 B$, red circle). In the far-surround configuration, the inner diameter of the surround annulus was $5^{\circ}$ (Fig. $2 \mathrm{C}$, red circle) and its outer diameter was $24^{\circ}$. The farsurround stimulus was partially masked so that the display from $1.5^{\circ}$ from the vertical meridian to the hemifield opposite to the stimuli had no luminance modulation (Fig. 2C). The comparison stimulus was identical to the center grating of the test stimulus except that its contrast was varied.

Data analysis. The orientation tuning of surround suppression was quantified as for V1 cells, but here spike rates were replaced with the corresponding perceived contrasts. In all figures, we report the mean of the four reversals for the four staircases (see above) and the SEs of these means. Bootstrapping was used for statistical testing because the number of subjects was relatively low. For statistical analysis of a given metric of orientation tuning (e.g., CV), data for near- and far-surround conditions were first pooled together. Corresponding to the number of subjects, two samples containing five values were randomly drawn with replacement, and the difference between the samples' means was computed. This procedure was repeated 10,000 times. The reported $p$ values refer to the probability that the difference in the resampled means exceeded the actual measured difference.

\section{Results}

We characterized the orientation tuning of the suppression arising from the near- and far-surround in macaque V1 and compared it with near- and far-surround suppression of perceived contrast in humans using similar visual stimuli at similar retinal eccentricities. 


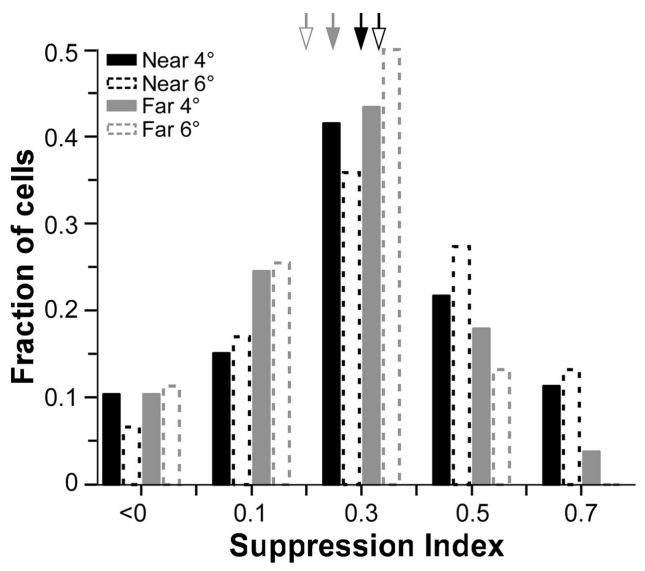

Figure 3. Distribution of suppression index across the cell population. SI was computed at $0^{\circ}$ center-surround orientation difference for near- and far-surround stimuli of 4 and $6^{\circ}$, as color coded in the legend. Arrows: population means $\left(n=106\right.$ cells) as follows. Near $4^{\circ}$ (solid black arrow $)=0.3 \pm 0.02 ;$ near $6^{\circ}$ (hollow black $)=0.33 \pm 0.02 ;$ far $4^{\circ}$ (solid gray) $=0.25 \pm 0.02$; far6 $6^{\circ}$ hollow gray) $=0.2 \pm 0.03$.

\section{Orientation tuning of surround suppression in macaque V1} neurons and human perception

Electrophysiology

Extracellular single-unit recordings were made from 106 neurons in parafoveal V1 of three macaque monkeys. Center-surround stimuli were presented in two configurations (near and far), each at two surround stimulus sizes (Fig. 2). The near-surround grating activated a region larger than the V1 cells' peak spatial summation area measured at low contrast (the latter corresponding to the average extent of V1 horizontal connections), but commensurate with the extent of the suppressive extraclassical surround of LGN afferents (Fig. 1). The far-surround grating activated the surround region beyond that activated by the nearsurround stimuli, i.e., beyond the range of horizontal and geniculocortical connections, but within the range of interareal feedback connections. We chose two different near- and farsurround grating sizes for this study $\left(4^{\circ}\right.$ and $\left.6^{\circ}\right)$, because we wished to match for each cell the strength of suppression evoked by iso-oriented stimuli in the near and far surround, and previous studies have shown that far-surround suppression is weaker than near-surround suppression (Shushruth et al., 2009). Matching the strength of iso-orientation suppression for near- and farsurround stimulation allowed us to eliminate the possible confound that differences in orientation tuning of near- and far-surround suppression could simply arise as a result of differences in their suppression strength. Figure 3 indeed shows similar distributions for near- and far-surround suppression strengths (expressed as SI) across our population, at the surround sizes used in this study.

Figure $4 A$ shows for one example $\mathrm{V} 1$ cell in layer $3 \mathrm{~B}$, the orientation tuning curves of near- and far-surround suppression. The response to the center grating presented alone is indicated by the purple horizontal line, while black and gray curves indicate the neuron response as a function of the difference in orientation between the center grating and the near- or far-surround grating, respectively. For this example cell, the near-surround grating suppressed the response to the center grating more strongly when the center and surround gratings were of similar orientation (orientation difference at or near $0^{\circ}$, or iso-orientation suppression) than when they were of orthogonal orientation (orientation difference at or near $90^{\circ}$, or ortho-orientation suppression). This
A Layer 3B

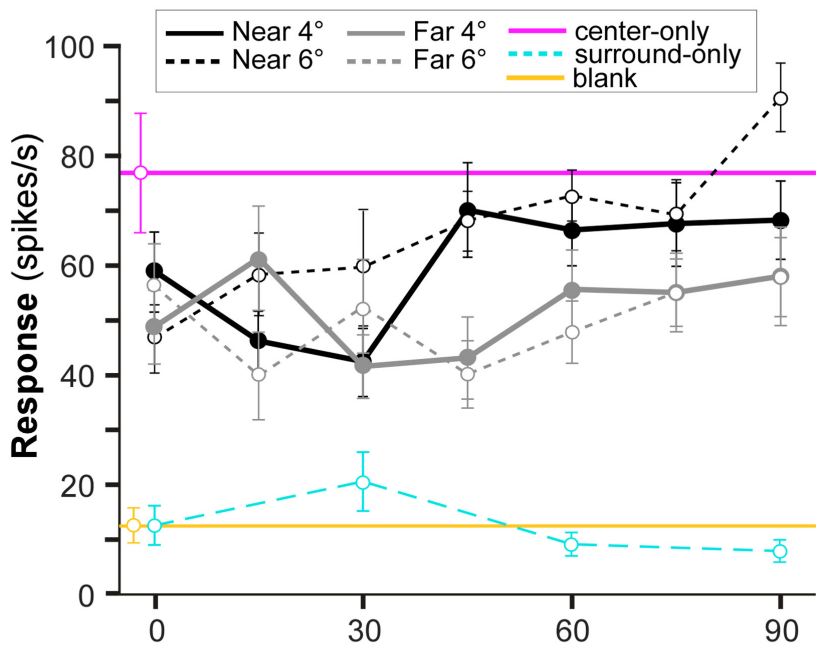

B

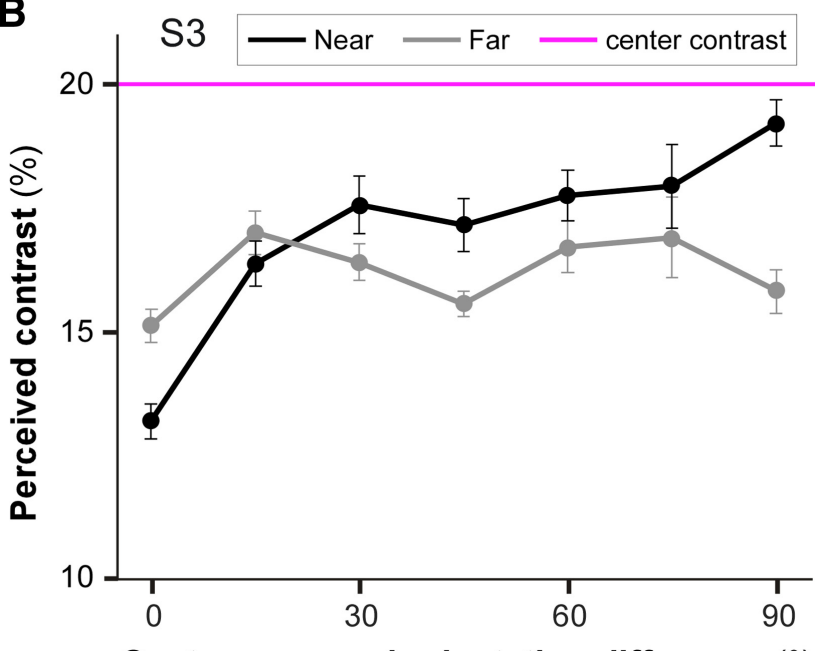

Center-surround orientation difference $\left(^{\circ}\right)$

Figure 4. Orientation tuning of near- and far-surround suppression for an example V1 cell and an example human subject. $\boldsymbol{A}$, Response of an example $V 1$ cell in layer $3 B$ as a function of the orientation difference between the center and surround gratings. The black curves indicate the near-surround responses, the gray curves the far-surround responses, the purple line the center-only response, the cyan curve the response to a near $4^{\circ}$ surround grating alone, and the yellow line the spontaneous activity. $\boldsymbol{B}$, Perceived contrast for subject $\mathrm{S} 3$ as a function of the center-surround orientation difference. The purple line represents the actual contrast of the center stimulus.

was the case for both the near $4^{\circ}$ (solid black curve) and near6 $6^{\circ}$ (dashed black curve) surround stimuli. The near6 ${ }^{\circ}$ stimulus in addition caused a slight facilitation at orthogonal centersurround stimulus orientations. For the same cell, far $4^{\circ}$ (solid gray curve) and far6 ${ }^{\circ}$ (dashed gray curve) surround gratings presented at iso-orientation exerted similar response suppression as iso-oriented near-surround stimuli; however, far-surround gratings of ortho-orientation were more suppressive than orthooriented near-surround gratings. As a result, the orientation tuning curves for far-surround suppression were flatter than the tuning curves for near-surround suppression, i.e., far-surround suppression was more broadly orientation-tuned than nearsurround suppression.

In Figure $5 A$, we show for the same cell as in Figure $4 A$ the orientation-tuning curve for near- and far-surround suppression, but here tuning is expressed as SI as a function of the differ- 


\section{PHYSIOLOGY}
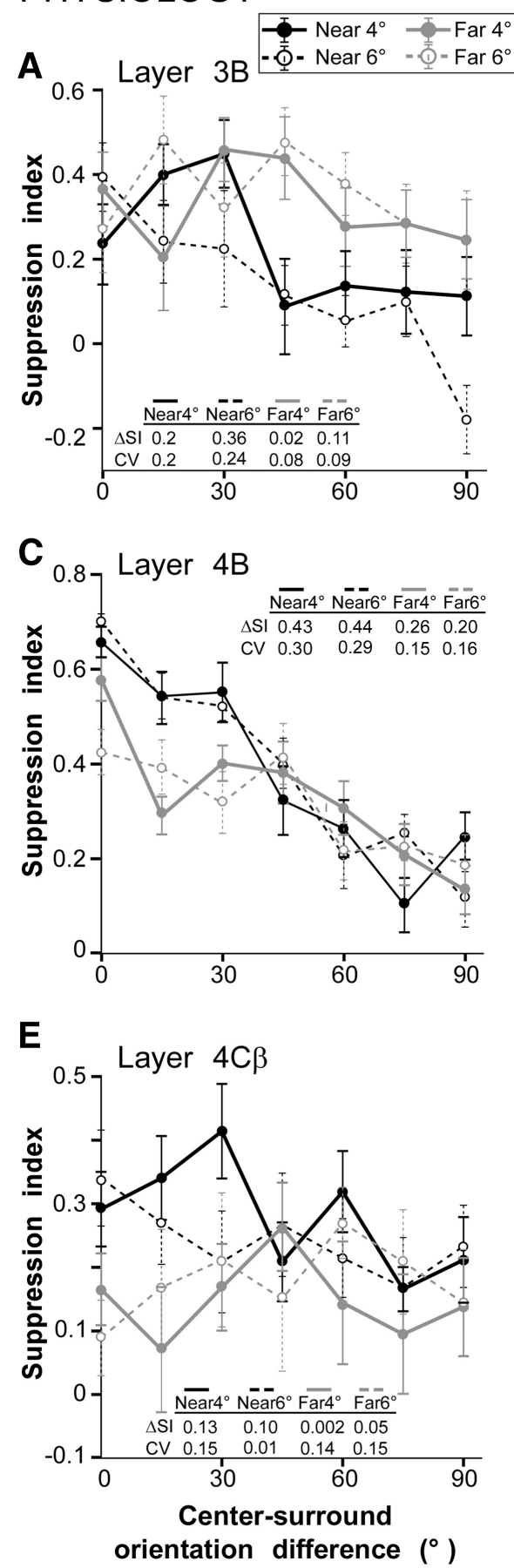
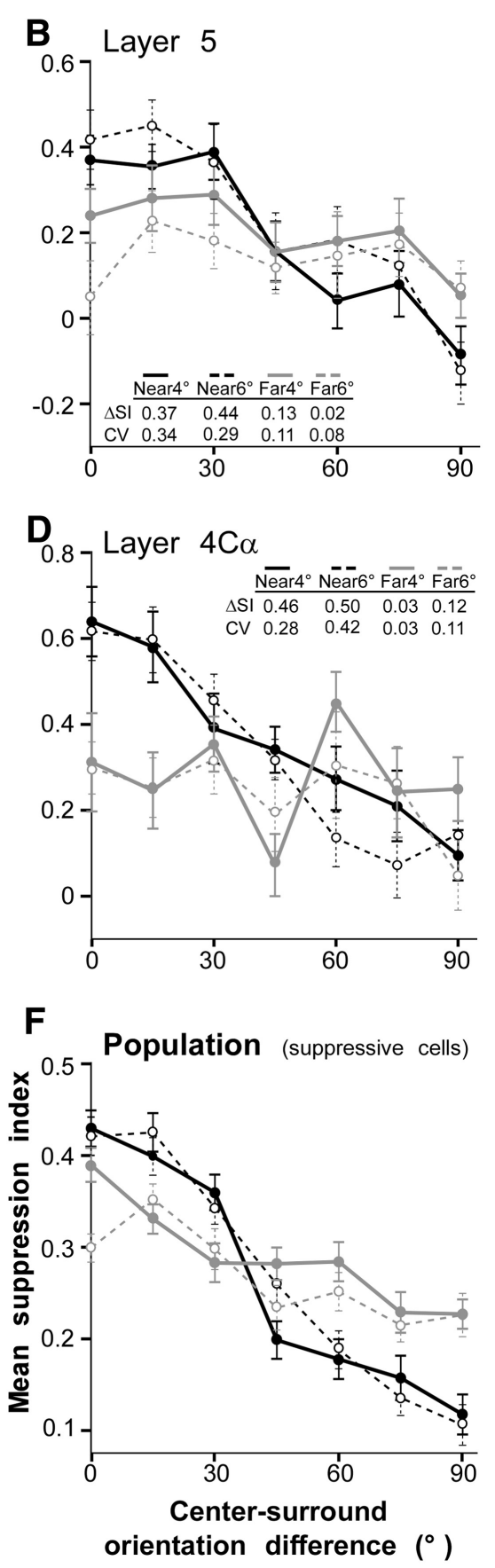

Figure 5. Orientation tuning of near- and far-surround suppression in V1. $\boldsymbol{A}-\boldsymbol{E}$, Orientation tuning curves of near-surround (black curves) and far-surround (gray curves) suppression for five example V1 cells located in different V1 layers (as indicated). Solid and dashed curves indicate measurements performed for different surround stimulus sizes as indicated in the legend. The tuning functions are expressed as suppression index as a function of the difference in orientation between the stimuli in the RF and surround. The tables in each panel indicate for the specificcell the values of $\Delta$ Sl and $C V$ for near-and far-surround suppression. $\boldsymbol{F}$, Average tuning curves at each surround condition, for the population of V1 cells that showed surround suppression. Error bars are SEM. Mean $\Delta \mathrm{SI}$ and $\mathrm{CV}$ for each surround conditions are as follows: $0.28 \pm 0.03$ and $0.24 \pm 0.02$ (near $4^{\circ} ; n=68$ cells), $0.3 \pm 0.03$ and $0.25 \pm 0.01$ (near6 ${ }^{\circ} ; n=68$ cells), $0.13 \pm$ 0.02 and $0.12 \pm 0.01$ (far $4^{\circ} ; n=65$ cells), $0.11 \pm 0.01$ and $0.14 \pm 0.01$ (far6 $6^{\circ} ; n=54$ cells).

ence in orientation between the center and surround gratings. Note that in this format, a lower response of the cell corresponds to a larger value of SI, i.e., stronger suppression, and thus the tuning function in Figure $5 A$ appears reversed compared with that in Figure $4 A$ (larger SI at iso-orientation and smaller SI at orthogonal orientation). All tuning functions in the reminder of the article are expressed in this format. Figure $5 B-E$ shows orientation tuning curves of near- and far-surround suppression for four additional representative V1 neurons at various laminar locations. For all cells in Figure 5, except the cell in Figure $5 E$ (in layer $4 \mathrm{C} \beta$ ), near-surround suppression was strongest at iso-orientation and weakest at orthogonal orientation. Similar results were obtained for near-surround suppression measured with either surround stimulus sizes $\left(4^{\circ}\right.$ or $6^{\circ}$ outer diameter). Far-surround suppression was significantly tuned for the layer $4 \mathrm{~B}$ cell (Fig. $5 C$ ), but poorly tuned for all other cells (Fig. $5 A, B, D, E$ ). Despite diversity in the strengths of near- and far-surround suppression across these cells, for all cells far-surround suppression showed broader orientation tuning than nearsurround suppression. To quantify this observation, we measured the $\Delta$ SI and CV for each cell (see Materials and Methods; values for each cell are reported in Fig. $5 A-E) . \Delta \mathrm{SI}$ is the difference in suppression index at iso-orientation versus at ortho-orientation, and thus has positive values when iso-orientation suppression is stronger than ortho-orientation suppression and negative values for stronger ortho- than iso-orientation suppression. The CV is a global measure of orientation selectivity, which can take values between 0 , indicating no orientation selectivity, and 1 , indicating that suppression occurs at only one surround orientation. Thus for example, for the layer $3 \mathrm{~B}$ cell in Figure $5 A$, the $\Delta$ SI dropped from 0.36 for nearsurround stimulation to 0.11 when only the far surround was stimulated, and the CV dropped from 0.24 to 0.09 (in the $6^{\circ}$ near- and far-stimulus condition). For this cell, the broader tuning of farsurround suppression compared with near-surround suppression was due to an increase in the strength of orthoorientation suppression, whereas isoorientation suppression was unchanged. For the layer 5 and layer $4 \mathrm{C} \alpha$ cells (Fig. $5 B, D)$, broader orientation tuning of the far surround, compared with the near-surround, resulted from both stronger ortho-orientation suppression and weaker iso-orientation suppression. Instead, for the layer $4 \mathrm{~B}$ cell (Fig. $5 \mathrm{C}$ ), the strength of iso-orientation suppression was markedly reduced for far-surround stimulation compared with near-surround stimulation, but ortho-orientation suppression was unchanged. Finally, the cell in layer $4 \mathrm{C} \beta$ (Fig. $5 E$ ) showed poor orientation tuning of both near- and far-surround suppression, with slightly weaker far-surround suppression at all 
orientations. These differences in orientation tuning of near- and far-surround suppression across cells were reflective of laminar-specific differences we observed across the V1 population. These laminar differences are analyzed in a later section of the Results. In the next section, we first describe the V1 population data regardless of the neurons' laminar location, i.e., pooling neuronal responses across V1 layers.

Figure $5 F$ shows the average tuning curves for near- and far-surround suppression for our V1 cell population, including only cells that showed surround suppression (defined as a mean response to center-surround orientation differences of $0^{\circ}$ and $15^{\circ}$ that was at least $1 \mathrm{SD}$ below the center-only response at the optimal orientation). The $\Delta$ SI $(0.28 \pm 0.03)$ and CV $(0.24 \pm 0.02)$ for near-surround suppression measured using surround gratings of $4^{\circ}$ outer diameter (near $4^{\circ}$ condition) were significantly higher than the $\Delta$ SI $(0.13 \pm 0.02)$ and $\mathrm{CV}(0.12 \pm 0.01)$ for far-surround suppression measured with surround gratings of $4^{\circ}$ inner diameter (far $4^{\circ}$ condition): $p<10^{-5}$ for both comparisons (unpaired Student's $t$ test). Similarly, $\Delta$ SI $(0.30 \pm 0.03)$ and CV $(0.25 \pm 0.01)$ for the near6 ${ }^{\circ}$ condition were significantly higher than $\Delta$ SI $(0.13 \pm$ $0.02)$ and $C V(0.12 \pm 0.01)$ for the far $6^{\circ}$ condition: $p<10^{-8}$ for both comparisons (Student's $t$ test). Thus, across the population of V1 cells with suppressive surrounds, far-surround suppression was more broadly tuned than near-surround suppression; this difference was due to significantly stronger ortho-orientation suppression (mean SI at center-surround orientation differences of $60^{\circ}, 75^{\circ}$, and $90^{\circ}$ for near versus far suppression; $p<$ 0.0007 for both $4^{\circ}$ and $6^{\circ}$ conditions, unpaired $t$ test), and slightly weaker, but significant, iso-orientation suppression (mean SI at center-surround orientation differences of $0^{\circ}, 15^{\circ}$, and $30^{\circ}$ for near versus far suppression; $p<0.009$ for both $4^{\circ}$ and $6^{\circ}$ conditions, unpaired $t$ test) in the far surround compared with the near surround.

\section{PSYCHOPHYSICS}
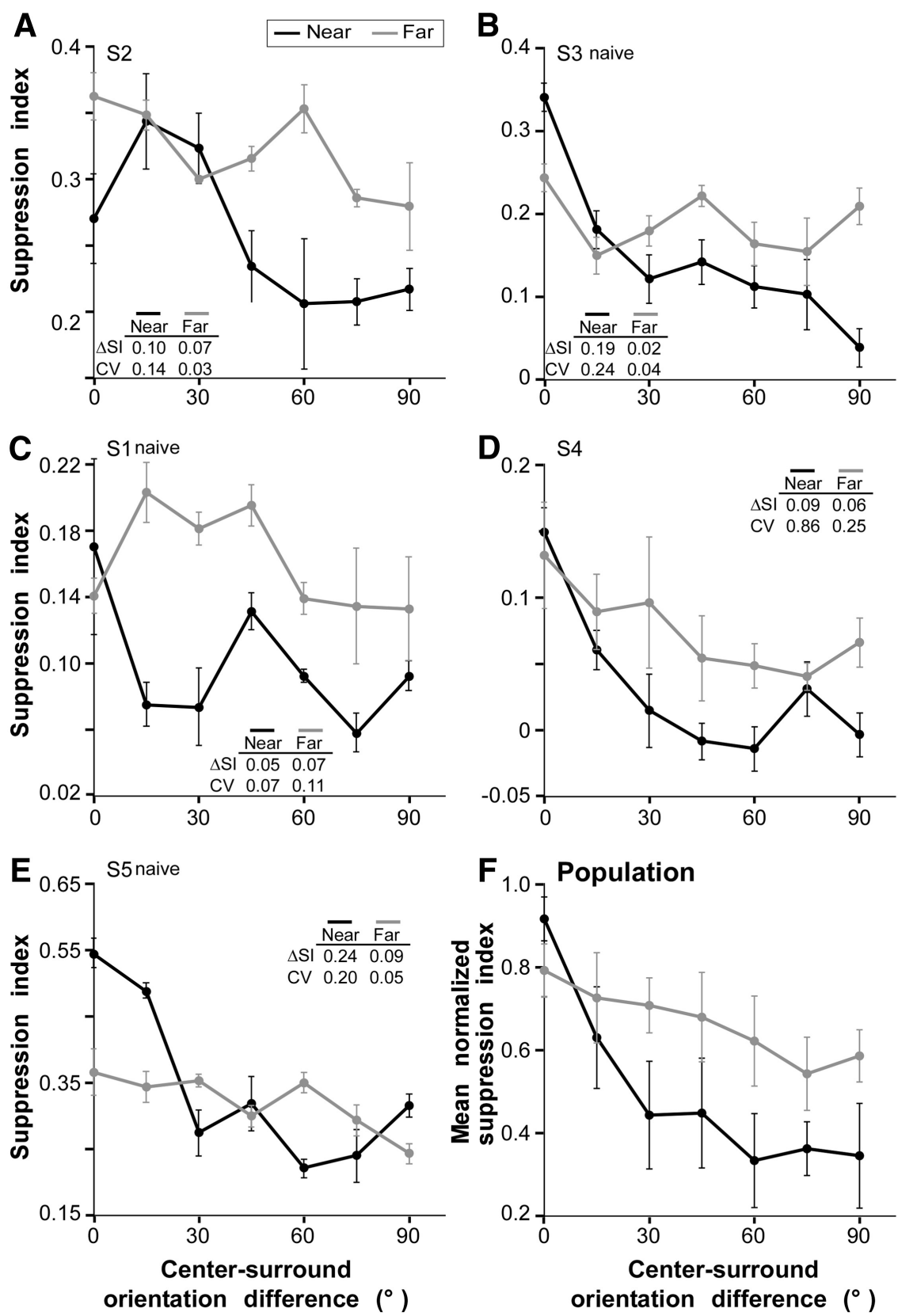

Figure 6. Orientation tuning of near- and far-surround suppression in human psychophysics. $A-E$, Orientation tuning curves of near-surround (black) and far-surround (gray) suppression for five human subjects, of whom three were naive. Suppression index measures the strength of suppression of the perceived contrast of the center grating exerted by the surround stimulus. $F$, Average tuning curve across the five subjects. Before averaging, the suppression index for each subject was normalized to the largest $\mathrm{SI}$ value for that subject. Mean $\Delta S \mathrm{Sl}$ and $\mathrm{CV}$ were as follows: $0.13 \pm 0.04$ and $0.3 \pm 0.14$ (near; $n=5$ subjects), $0.05 \pm 0.01$ and $0.09 \pm 0.04$ (far; $n=5$ subjects).

\section{Psychophysics}

Figure $4 B$ shows for one example subject (S3) the psychophysical data obtained using similar stimuli (Fig. $2 B, C$ ) as used for the electrophysiological experiments. Here the tuning curves are expressed as the perceived contrast of the center grating as a function of the difference in orientation between the center and surround gratings of the test stimulus. The purple line indicates the actual contrast of the center grating (20\%). The same data for subject S3 are shown in Figure $6 B$ plotted as SI versus centersurround orientation difference. SI was computed as for V1 cells (see Materials and Methods), but here responses (spike rates) were replaced with the corresponding perceived contrasts. Figure 6, $A$ and $C-E$, shows the orientation tuning of surround suppression in each of the four remaining subjects. In all subjects, both near- and far-surround stimuli suppressed the perceived contrast of the center grating more strongly when the center and surround stimuli were of similar orientation; increasing the centersurround orientation difference decreased suppression strength. Thus, despite variability across subjects in suppression strengths and sharpness of orientation tuning, both near- and far-surround 

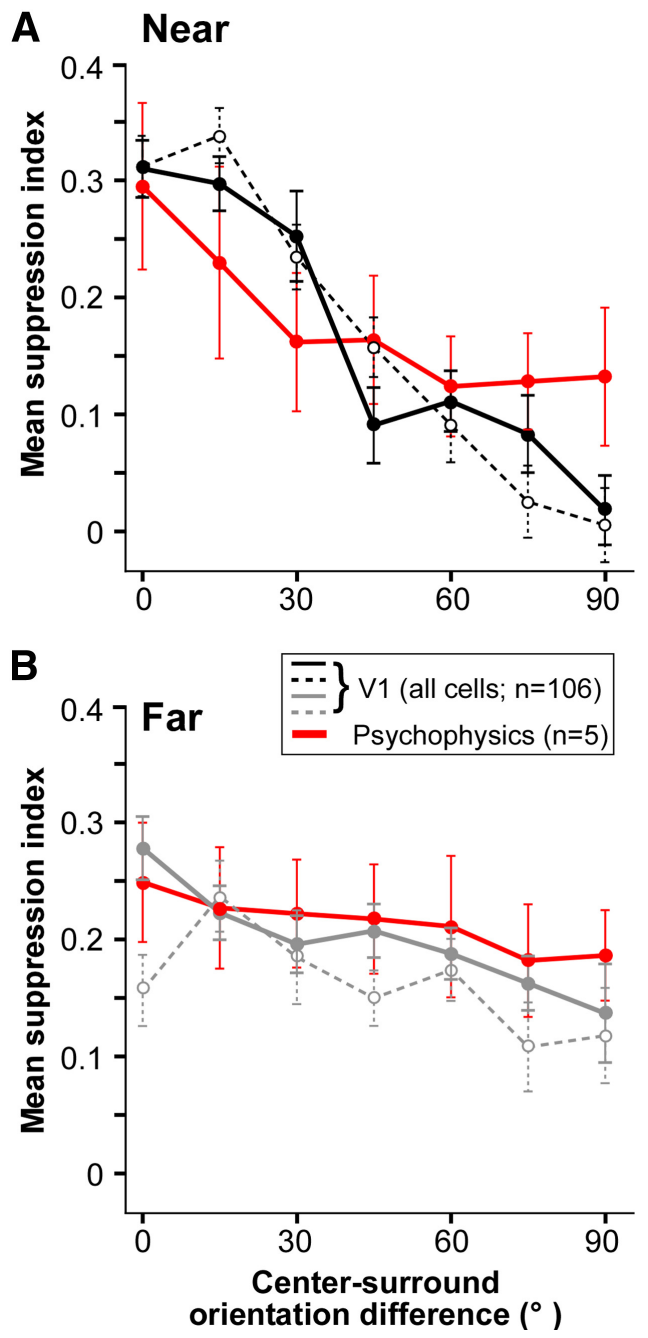

Figure 7. Comparison of orientation tuning of suppression in V1 cells and human psychophysics. $\boldsymbol{A}, \boldsymbol{B}$, Average population tuning curves of near-surround $(\boldsymbol{A})$ and far-surround $(\boldsymbol{B})$ suppression for all V1 cells $(n=106)$, including suppressive and nonsuppressive (black curves, near suppression; gray curves, far suppression), and for all human subjects ( $n=5$; red curves). Other conventions are as in Figures 5 and 6 ).

suppression were tuned for orientation (for all subjects $\Delta$ SI has positive values and $\mathrm{CV}>0$ ). However, as the center-surround orientation difference increased, suppression strength decreased more rapidly in the near-surround compared with the farsurround condition, and this difference persisted when tuning curves were averaged across subjects (Fig. $6 F$ ). In Figure $6 F$, the data from individual subjects was first normalized to the largest SI value for that subject, to account for intersubject differences in surround suppression strengths, and then averaged over the subjects. The $\Delta$ SI $(0.13 \pm 0.04)$ and CV $(0.30 \pm 0.14)$ for nearsurround suppression were significantly higher than the $\Delta \mathrm{SI}$ $(0.05 \pm 0.01)$ and $\mathrm{CV}(0.09 \pm 0.04)$ for far-surround suppression $(p<0.05$, bootstrap test). As for V1 cells, in human perception the orientation tuning of the suppression was broader in the far compared with the near-surround, and this was due to surround orientations nearer to orthogonal exerting stronger suppression in the far than in the near surround.

Comparison of V1 neuronal responses and human psychophysics In Figures 7 and 8, we compare the orientation tuning of nearand far-surround suppression in psychophysics and electrophys-
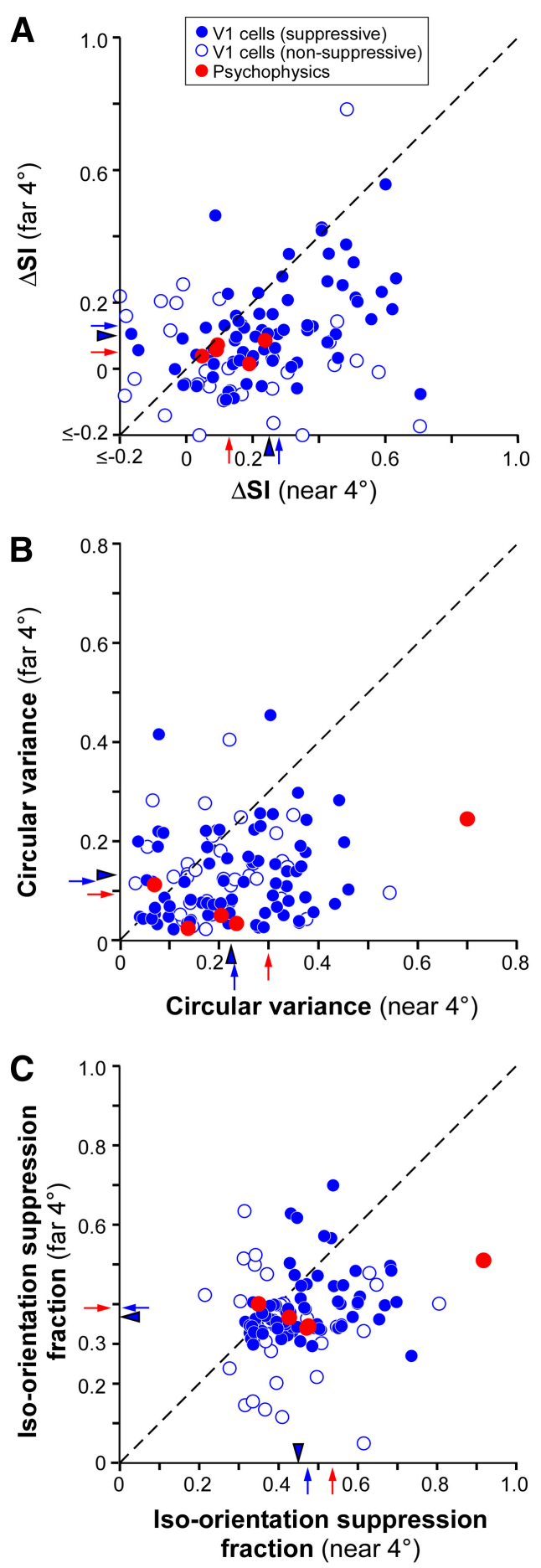

Figure 8. Comparison of orientation selectivity of suppression and iso-orientation suppression fraction in $V 1$ cells and human psychophysics. $A$, Scatterplot of the $\Delta S$ I of suppression in the near versus far surround. $\boldsymbol{B}$, Scatterplot of the $C V$ of suppression in the near versus far surround. C, Scatterplot of iso-orientation suppression fraction in the near versus far surround. Only near $4^{\circ}$ and far $4^{\circ}$ conditions are shown. Empty blue dots, V1 cells that showed no suppression in the near and far surround; solid blue dots, V1 cells that showed at least one form of suppression (near or far); red dots, psychophysics data; red arrows, means of psychophysics data; solid blue arrows, means of suppressive cells; arrowheads, means of all V1 cells (suppressive and nonsuppressive).

iology. It is important to emphasize that this comparison is qualitative because it is made between two different types of data.

In Figure 7, we compare the orientation tuning of nearsurround (Fig. 7A) and far-surround (Fig. 7B) suppression in 
macaque V1 cells and human observers. In contrast to the results reported above, here the suppression index was averaged across the whole population of V1 cells $(n=106)$, including suppressive and nonsuppressive cells, as we reasoned that all cells would likely contribute to the psychophysical results. The suppression index for the psychophysical data was averaged across the five human subjects without being normalized within each subject. In both V1 and human perception, the strength of near-surround suppression decreased steeply as the orientation difference between the stimuli in the center and surround increased (Fig. 7A). In the $\mathrm{V} 1$ cell population, the suppression index decreased from 0.31 (in both near $4^{\circ}$ and near $6^{\circ}$ conditions) at iso-orientation to 0.09 $\left(\right.$ near $\left.4^{\circ}\right)$ and $0.16\left(\right.$ near6 $\left.6^{\circ}\right)$, respectively, at a center-surround orientation difference of $45^{\circ}$. In human subjects, for the same change in center-surround orientation difference, the suppression index decreased from 0.29 to 0.16 . However, suppression at $90^{\circ}$ or near $-90^{\circ}$ orientation difference was modestly higher in human subjects compared with V1 cells. In both V1 cells and human subjects, far-surround suppression showed modest orientation tuning (Fig. $7 B$ ). In V1 cells, the suppression index decreased from $0.28\left(\right.$ far $\left.4^{\circ}\right)$ and $0.16\left(\right.$ far $\left.6^{\circ}\right)$ at iso-orientation, to $0.21\left(\right.$ near $\left.4^{\circ}\right)$ and $0.15\left(\right.$ far $\left.6^{\circ}\right)$ at a center-surround orientation difference of $45^{\circ}$. In human subjects, the corresponding decrease in suppression index was from 0.25 to 0.22 . Thus, the orientation tuning of near- and far-surround suppression showed a similar trend in V1 neurons and human perception. In both, nearsurround suppression was more sharply tuned than far-surround suppression, as measured by the $\Delta$ SI or by the CV. Specifically, for all V1 cells, the mean $\Delta$ SI for near $4^{\circ}(0.25 \pm 0.03)$ and near6 ${ }^{\circ}$ $(0.31 \pm 0.03)$ was significantly higher than the mean $\Delta$ SI for far $4^{\circ}$ $(0.1 \pm 0.02)$ and far6 $6^{\circ}(0.08 \pm 0.02)$, respectively, with $p<10^{-8}$ for both comparisons (paired Student's $t$ test). For the nonnormalized psychophysical functions, the mean $\Delta$ SI for near $(0.13 \pm 0.04)$ and far $(0.05 \pm 0.01)$ suppression were significantly different, with $p<0.05$ (bootstrap test). For all V1 cells, the mean $\mathrm{CV}$ for near $4^{\circ}(0.22 \pm 0.01)$ and near $6^{\circ}(0.25 \pm 0.01)$ was significantly higher than mean $\mathrm{CV}$ for far $4^{\circ}(0.13 \pm 0.01)$ and far6 ${ }^{\circ}$ $(0.16 \pm 0.01)$, respectively, with $p<10^{-9}$ for both comparisons. For the non-normalized psychophysical functions, the mean CV for near $(0.3 \pm 0.14)$ and far $(0.09 \pm 0.04)$ suppression were significantly different, with $p<0.05$ (bootstrap test).

Figure $8 A$ shows a scatterplot of $\Delta$ SI for near versus farsurround suppression for both V1 cells and human subjects. Only the near $4^{\circ}$ and far $4^{\circ}$ conditions are shown, but results were similar for the $6^{\circ}$ near and far conditions. Most dots lie below the diagonal line indicating sharper orientation selectivity of near versus far-surround suppression (mean values and statistical significance of the difference are reported above or in Figs. $5 F, 6 F$ ). Figure $8 B$ shows a scatterplot of $C V$ for near versus far-surround suppression for both V1 cells and human subjects. Most cells and four of five subjects are located below the diagonal line, again, indicating sharper orientation selectivity of near- than farsurround suppression for most single cells and human subjects (mean values and statistical significance of the difference are reported above or in Figs. $5 F, 6 F$ ).

We also measured the fraction of suppression strength occurring at and near iso-orientation, a metric that, unlike $\Delta$ SI, is not affected by the absolute value of suppression strength. Unlike CV, which is a global measure of the shape of the tuning curve, the iso-orientation suppression fraction is a local measure of the sharpness of the tuning curve around its peak. The latter was calculated by first fitting a Gaussian function to the orientation tuning curve of surround suppression (i.e., the SI versus orientation-difference curves-e.g., Fig. 5) for each cell, and then measuring from these fits the area under the curve between $0^{\circ}$ and $30^{\circ}$ orientation difference as a fraction of the total area under the tuning curve. A higher fractional value indicates that a larger fraction of the suppression occurs between $0^{\circ}$ and $30^{\circ}$ centersurround orientation differences, indicating sharper orientation tuning. Figure $8 \mathrm{C}$ reports the results of this analysis in the form of a scatterplot of iso-orientation suppression fraction for near versus far surround, for both V1 cells and human subjects. Again only the $4^{\circ}$ surround conditions are shown, but results for the $6^{\circ}$ condition were similar. Most points lie below the diagonal, indicating that for most cells and human subjects a higher fraction of the total suppression occurs at iso-orientation in the near surround compared with the far surround, and thus that nearsurround suppression is more sharply orientation-tuned than far-surround suppression. The mean iso-orientation suppression fraction for the near surround $\left(0.45 \pm 0.01\right.$ and $0.46 \pm 0.01$ for $4^{\circ}$ and $6^{\circ}$ surround sizes, respectively, including all cells) was significantly higher than for the far surround $(0.37 \pm 0.01$ and $0.38 \pm$ 0.01 , respectively), with $p<10^{-7}$ for both comparisons (paired $t$ test). Similar results were seen in the psychophysics data. The mean iso-orientation suppression fraction was $0.52 \pm 0.10$ for the near surround and $0.38 \pm 0.03$ for the far surround, and this difference was statistically significant ( $p<0.01$, bootstrap test).

\section{V1 laminar specificity in orientation tuning of near- and far-surround suppression}

Different circuits have different laminar specificity, and there are pronounced differences in receptive field properties across V1 layers in macaque. Laminar-specific differences have also been observed in the spatial extent and strength of surround suppression that may reflect laminar differences in connectivity (Ichida et al., 2007; Shushruth et al., 2009). Thus, to make more direct comparison with anatomical data, we examined the tuning of near- and far-surround suppression across V1 layers. Figure 9 shows the tuning curves for the population of suppressive cells only (mean SI vs center-surround orientation difference) for both near- and far-surround suppression in each V1 layer. There were differences in orientation tuning and suppression strength across layers, but in all layers near-surround suppression was more sharply tuned than far-surround suppression. In all layers, the $\Delta \mathrm{SI}$ and/or CV (values reported in Table 1) for near-surround suppression were significantly higher than for farsurround suppression in at least one surround size condition $\left(4^{\circ}\right.$ or $\left.6^{\circ}\right)\left(\Delta\right.$ SI $p<0.05$ for the near $4^{\circ}-$ far $4^{\circ}$ comparison in layers $3 \mathrm{~B}, 4 \mathrm{C} \alpha$, and $5-6$, and for the near $6^{\circ}-$ far $6^{\circ}$ comparison in all layers except $2-3 \mathrm{~A}$ and $4 \mathrm{~A})$. Although there was no significant difference in near versus far $\Delta \mathrm{SI}$ in layers $2-3 \mathrm{~A}$, and $4 \mathrm{~A}$ for either surround size condition, the $\mathrm{CV}$ for near- and far-surround suppression in these layers was significantly different in at least one condition ( $p<0.05$; unpaired $t$ test).

In all layers, except $4 \mathrm{~A}$ and $4 \mathrm{C} \beta$, the broader tuning of farsurround suppression was due to stronger ortho-orientation suppression in the far than in the near surround. Iso-orientation suppression was of similar strength in the near and far surround in layers $2-3 \mathrm{~A}, 4 \mathrm{~A}$, and $5 / 6$. However in layer $3 \mathrm{~B}, 4 \mathrm{~B}$, and $4 \mathrm{C} \alpha$ iso-orientation suppression was slightly weaker in the far than in the near surround, and this also contributed to the broader orientation tuning of far suppression in these layers.

Figure 10 shows the distribution of $\Delta \mathrm{SI}$ and CV in different V1 layers. The same parameters are shown in Figure 11 in a scatterplot as a function of cortical depth. For near-surround suppression the $\Delta \mathrm{SI}$ was higher $(>0.3)$ in layers $3 \mathrm{~B}, 4 \mathrm{~B}$, and $4 \mathrm{C} \alpha$, and weakest in layer $4 \mathrm{~A}$ and below $4 \mathrm{C} \alpha$, and this differ- 

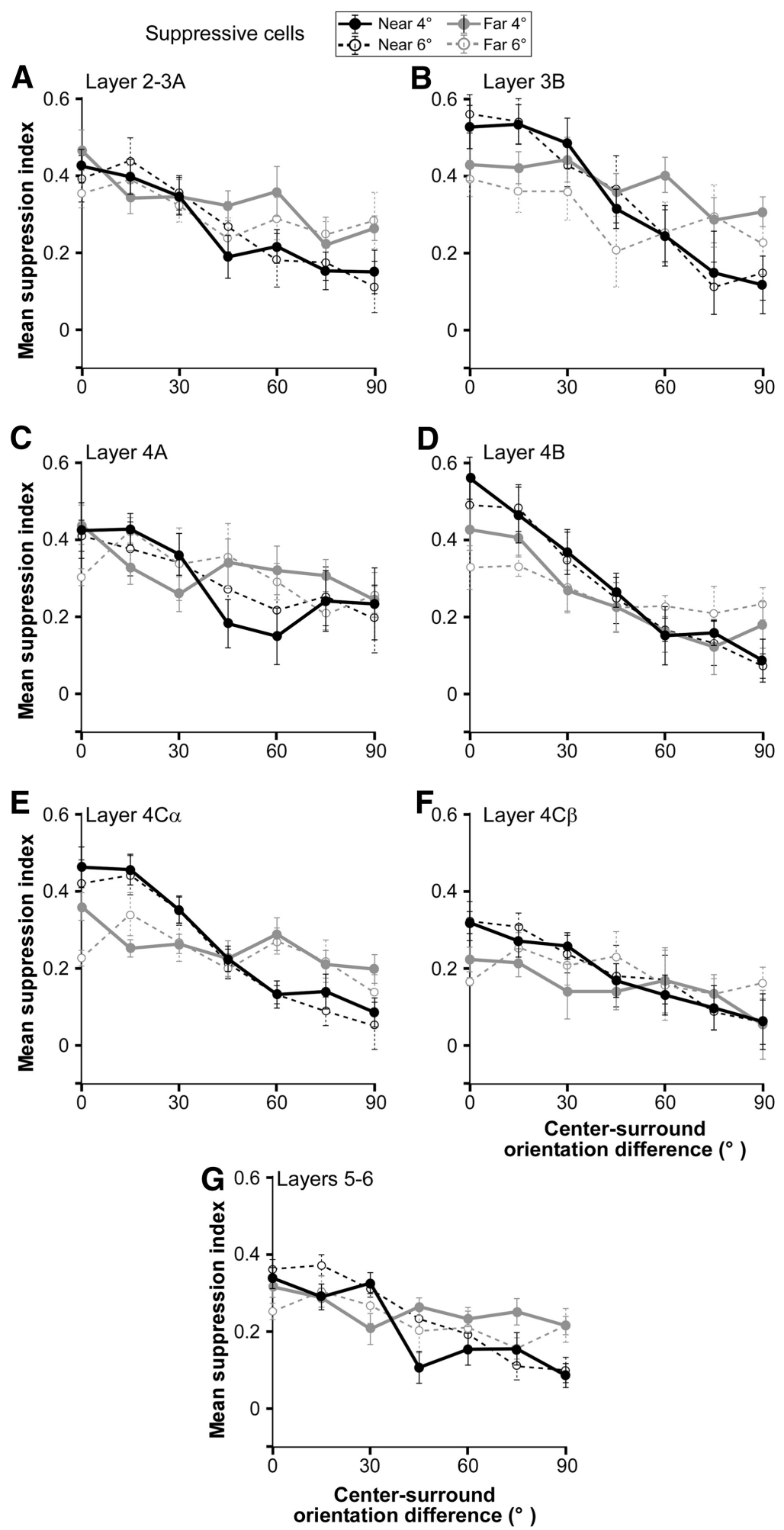

Figure 9. Orientation tuning of near- and far-surround suppression in different V1 layers. $\boldsymbol{A}-\boldsymbol{G}$, Average orientation tuning curves of near-surround (black curves) and far-surround (gray curves) suppression for population of V1 neurons recorded in specific $\mathrm{V} 1$ layers (as indicated). Only cells that showed suppression in a given stimulus condition were included in the tuning curve for that condition. Conventions are as in Figure 5. Mean $\Delta S \mathrm{SI}$ and $\mathrm{CV}$ values for each layer are reported in Table 1.

ence was statistically significant $(p=0.0031$, Kruskal-Wallis test). The CV of near-surround suppression was largest in layer $4 \mathrm{C} \alpha$ but not significantly different from that in other layers, indicating that near-surround suppression shows at least some tuning in all layers. The scatterplot of CV (Fig. 11B) shows a large spread of CV values across layers, with cells having CV around 0.4 located in most layers. For far-surround suppression the $\Delta$ SI was highest $(>0.2)$ in layer $4 \mathrm{~B}$ and weakest in layers $5 / 6$, and the difference between these two layers was statistically significant $(p<0.0036$, Kruskal-Wallis test corrected for multiple comparisons). The scatterplot in Figure $11 \mathrm{~A}$ shows that cells with the largest values of $\Delta$ SI (near 0.4 ) were located in layers $4 \mathrm{~B}$ and above (except for $4 \mathrm{~A})$. The CV of far-surround suppression was significantly larger in layer $4 \mathrm{~B}$ and weaker in layers 5-6 compared with all other layers ( $p=0.04$, Kruskal-Wallis test), and cells with the lowest values of CV were located in layers 5-6. The difference in CV between layer $4 \mathrm{~B}$ and $5 / 6$ for far-surround suppression was highly statistically significant $(p<$ 0.002 , Kruskal-Wallis test corrected for multiple comparisons).

\section{Discussion}

We found that the orientation tuning of surround suppression depends on the spatial separation between center and surround stimuli in both macaque V1 and human perception. Specifically, the suppression caused by near-surround stimulation was more sharply orientation tuned than the suppression caused by farsurround stimulation. These results support the idea that the near and far surround are two distinct regions generated by different neural circuits with distinct orientation specificities. The similarity between electrophysiological and psychophysical results also point to an important relationship between surround suppression in V1 neurons and human perception. In V1, we additionally found laminar differences in the orientation tuning of both the near and far surround, suggesting laminar differences in the orientation specificities of their underlying circuitry.

\section{Near- and far-surround suppression differ in orientation tuning}

Far-surround suppression is weaker than near-surround suppression in both V1 (Levitt and Lund, 2002; Shushruth et al., 2009) and perception (Cannon and Fullenkamp, 1991; Saarela and Herzog, 2008), but these differences in suppression strength cannot explain the different orientation tuning of near- and farsurround suppression seen in our data. This is because farsurround suppression was stronger than near-surround suppression at near-ortho-orientations. A previous study in cat 
Table 1. Orientation tuning of surround suppression in different V1 layers: mean $\Delta \mathrm{SI}$ and mean CV

\begin{tabular}{|c|c|c|c|c|c|c|c|c|c|c|c|c|c|}
\hline \multirow[b]{2}{*}{ Layer } & \multicolumn{3}{|c|}{ Near surround $\left(4^{\circ}\right)$} & \multicolumn{3}{|c|}{ Near surround $\left(6^{\circ}\right)$} & \multicolumn{3}{|c|}{ Far surround $\left(4^{\circ}\right)$} & \multicolumn{3}{|c|}{ Far surround $\left(6^{\circ}\right)$} & \multirow[b]{2}{*}{ Figures } \\
\hline & $N$ & mean $\Delta S \mathrm{SI}$ & mean CV & $N$ & mean $\Delta S \mathrm{SI}$ & mean CV & $N$ & mean $\Delta \mathrm{SI}$ & mean CV & $N$ & mean $\Delta S \mathrm{SI}$ & mean CV & \\
\hline $3 A$ & 14 & $0.26=$ & 019 & 13 & $0.27 \pm 0.08$ & 0.24 & 13 & 011 & 2 & 12 & 34 & 0.1 & $9 A_{1}$ \\
\hline $3 B$ & 11 & $0.40=$ & 0.21 & 10 & $0.42 \pm 0.08$ & 0.2 & 10 & & & 7 & 0.03 & & $9 B, 10,11$ \\
\hline A & 6 & $0.19 \pm 0.08$ & $0.26 \pm 0.05$ & 7 & $0.17 \pm 0.06$ & $0.18 \pm 0.03$ & 7 & $0.11 \pm 0.02$ & $0.10 \pm$ & 7 & $0.13 \pm 0.04$ & 0.16 & $9 C, 10,11$ \\
\hline 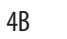 & 7 & $0.39 \pm 0.07$ & $0.25 \pm 0.04$ & 8 & $0.38 \pm 0.07$ & $0.25 \pm 0.04$ & 8 & $0.27 \pm 0.05$ & $0.23 \pm$ & 6 & $0.11 \pm 0.04$ & $0.13=$ & $9 D, 10,11$ \\
\hline$\alpha$ & 8 & $0.35 \pm 0.06$ & $0.29 \pm 0.04$ & 9 & $0.36 \pm 0.07$ & $0.34 \pm$ & 6 & $0.10 \pm$ & $0.09 \pm$ & 7 & $0.11 \pm$ & 0.11 & $9 E, 10,11$ \\
\hline$C \beta$ & 4 & $0.22 \pm 0.04$ & $0.25 \pm 0.06$ & 4 & $0.24 \pm 0.01$ & $0.24 \pm 0.04$ & 4 & $0.12 \pm$ & $0.16 \pm$ & 3 & $0.06 \pm 0.02$ & $0.19 \pm$ & $9 F, 10,11$ \\
\hline $5 / 6$ & 17 & $0.19 \pm 0.03$ & $0.24 \pm 0.03$ & 16 & $0.26 \pm 0.03$ & $0.23 \pm 0.02$ & 16 & $0.07 \pm 0.03$ & $0.08 \pm 0.01$ & 11 & $0.09 \pm 0.03$ & $0.16 \pm 0.02$ & $9 G, 10,11$ \\
\hline
\end{tabular}

$N$, Number of cells.
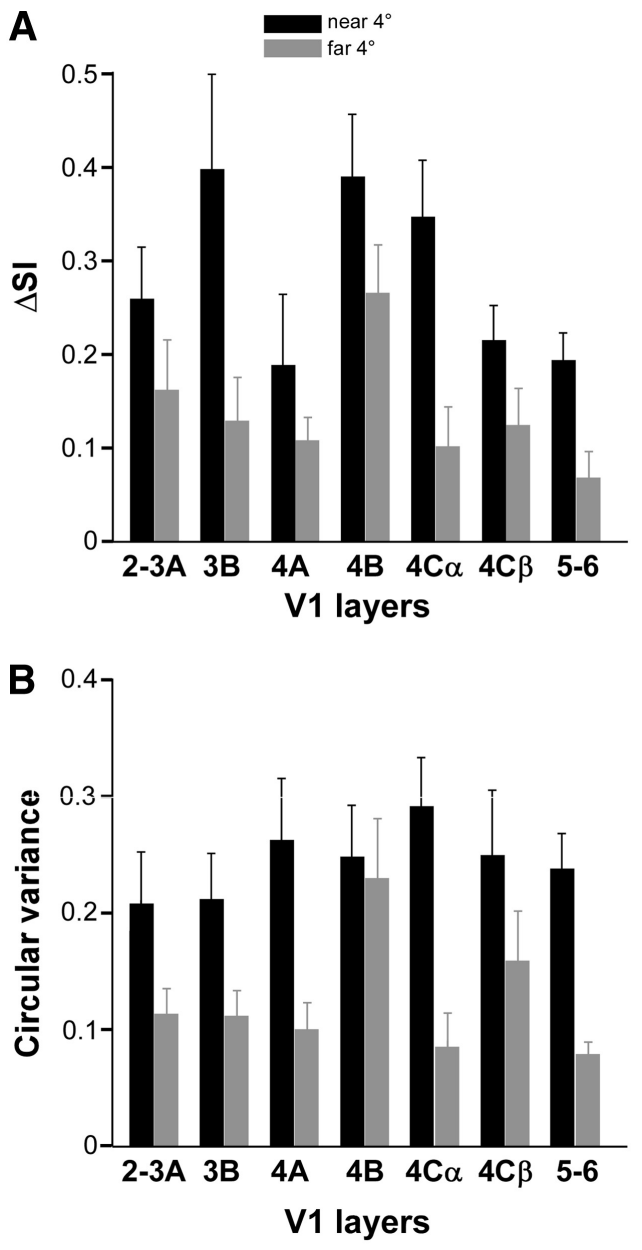

Figure 10. Orientation selectivity of near- and far-surround suppression in different $\mathrm{V} 1$ layers. $\boldsymbol{A}, \boldsymbol{B}$, Distribution of $\Delta S \mathrm{SI}(\boldsymbol{A})$ and $C V(\boldsymbol{B})$ for near-surround (black) and far-surround (gray) suppression across $\mathrm{V} 1$ layers. Only the near $4^{\circ}$ and far $4^{\circ}$ stimulus conditions are included and only cells that showed surround suppression in each condition.

V1 reported that the suppression caused by far-surround stimulation was more broadly orientation tuned than the suppression caused by full surround stimulation (near plus far) (HashemiNezhad and Lyon, 2012). However, compared with full surround stimulation, far-surround stimulation resulted in weaker isoorientation suppression, but similar ortho-orientation suppression strength. Thus, broader tuning of far-surround suppression, in this study, could have resulted from weaker far-surround suppression, an interpretation that cannot explain our findings. These different results are attributable to the different stimulus configurations used in the two studies. We compared nearsurround versus far-surround stimulation, whereas Hashemi-
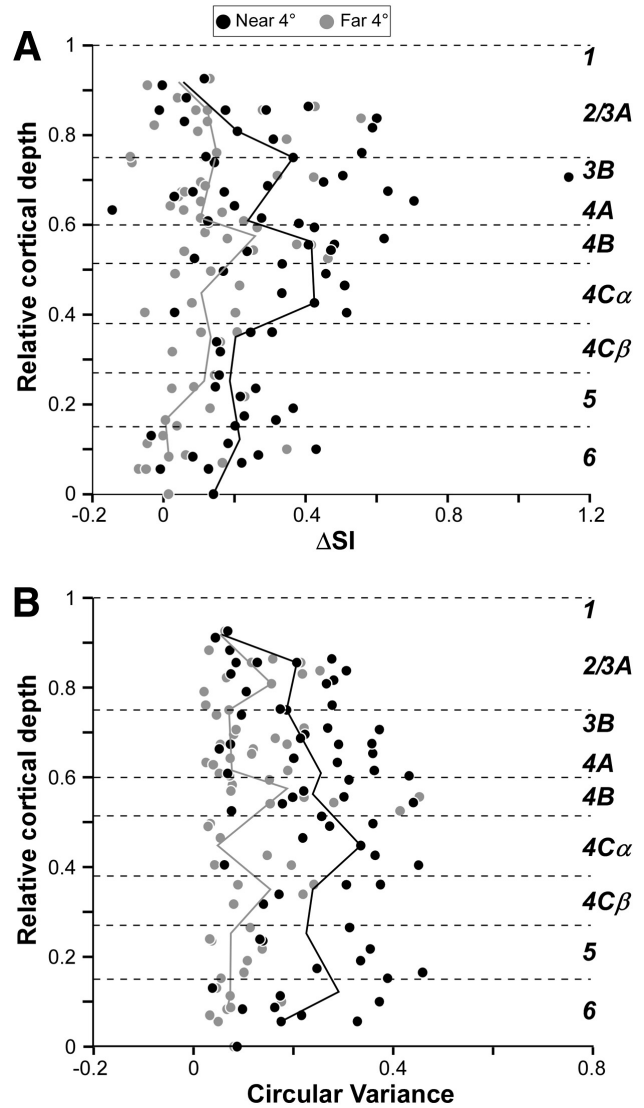

Figure 11. V1 laminar distribution of orientation selectivity of near-and far-surround suppression. $\boldsymbol{A}, \boldsymbol{B}$, Scatterplot of $\Delta \mathrm{SI}(\boldsymbol{A})$ and $\mathrm{CV}(\boldsymbol{B})$ as a function of cortical depth for near-surround (black dots) and far-surround (gray dots) suppression for the population of $\mathrm{V} 1$ cells showing suppression in each condition (onlynear $4^{\circ}$ and far $4^{\circ}$ included). The dashed horizontal lines mark V1 layer boundaries, and the cortical layers are indicated to the right of the plots. Solid black and gray vertical lines: medians of the V1 cell sample calculated at intervals of $10 \%$ of total cortical depth.

Nezhad and Lyon (2012) compared near-surround versus fullsurround stimulation, and thus did not isolate the tuning of suppression from the near surround. Polat and Sagi (1993) examined the effects on contrast detection of small Gabor patches placed at various distances from a target Gabor. They found both suppressive and facilitatory effects of flankers in the near surround $\left(\leq 3^{\circ}\right.$ separation), whose orientation tuning resembled that of near-surround suppression in our psychophysical study. However, in their study, flankers in the far surround $\left(\sim 3.6^{\circ}\right.$ from the target) had no effect on target detection, likely due to the weak surround stimulation exerted by such small stimuli. In contrast, we used large gratings likely to have stronger effects. Mizobe et al. (2001), instead, using Gabor stimuli in cat V1 observed both near 
and far (up to $12^{\circ}$ ) surround effects, but did not examine the tuning of far-surround suppression.

We found sharper tuning of near-surround suppression than previous studies. In our cell population, there was $>90 \%$ decrease in suppression strength when the surround stimulus orientation was changed from iso-oriented to orthogonal. This contrasts with the $30-35 \%$ decrease found in previous studies (Cavanaugh et al., 2002; Hashemi-Nezhad and Lyon, 2012). Broader tuning of suppression in these studies was likely due to concomitant stimulation of the near and far surround, and is thus consistent with our findings.

Petrov et al. (2005) studied surround suppression of contrast detection with stimuli likely activating mainly the near surround of V1 neurons. They found that suppression was negligible for center-surround orientation differences $\geq 45^{\circ}$. In our psychophysical and electrophysiological data, near-surround suppression was still present at $45^{\circ}$ orientation difference. This discrepancy is attributable to different center stimulus contrasts used in the two studies. Psychophysics (Nurminen et al., 2010) and single-cell recordings (Schwabe et al., 2010) have shown that suppression strength decreases at lower center contrast. Thus, it is likely that at the very low center contrast (at threshold) used by Petrov et al. (2005), weak suppressive effects from orthogonal surround stimuli disappear.

Cannon and Fullenkamp (1991), using eight cycles-wide surround stimuli, found that the strength of surround suppression decreases steeply between center-surround orientation differences of $0^{\circ}$ and $15^{\circ}$, but more gradually at larger orientation differences. They concluded that surround suppression arises from two distinct mechanisms, one narrowly orientation tuned, the other broadly tuned. Our results are consistent with their hypothesis, but further indicate that the narrowly tuned mechanism is spatially restricted, while the broadly tuned mechanism is spatially widespread.

\section{Correlation between human psychophysics and V1 physiology}

Previous studies found positive correlations between contextual effects in human vision and the response of single V1 cells (Kapadia et al., 1995, 1999; Li et al., 2000). However, in those studies it was unclear whether the stimuli intended to activate the surround also encroached onto the RF (as defined in our study). Moreover, these studies compared the mean firing rates of V1 neurons to subjects' performance in detection and discrimination tasks. This is problematic because performance in these tasks relates to the noise level and slope of the underlying neural responses (Geisler and Albrecht, 1997). In contrast, we used stimuli clearly confined to the surround, and a contrast-matching task, which is better suited to compare mean neuronal firing rates with psychophysical performance, because performance in this task relates to the magnitude of the underlying neural response (Chen and Tyler, 2002). Although it is not straightforward to compare psychophysics and electrophysiological data, our results nevertheless demonstrate a striking similarity between the tuning of surround effects in human perception and V1 cells.

\section{Anatomical circuits underlying the orientation tuning of near- and far-surround suppression}

We previously suggested that near-surround suppression results predominantly from both untuned surround suppression of geniculocortical afferents and tuned suppression from intra-V1 horizontal connections, while far-surround suppression is generated exclusively by interareal feedback (Angelucci and Bress- loff, 2006; Angelucci and Shushruth, 2013). Here, we have found that near-surround suppression is more sharply tuned than farsurround suppression, and is most narrowly tuned in layers $3,4 \mathrm{~B}$, and $4 \mathrm{C} \alpha$. Because the suppression contributed by geniculocortical afferents to V1 is untuned (Solomon et al., 2002; Webb et al., 2002; Bonin et al., 2005) or less tuned (Ozeki et al., 2009) for orientation than V1 suppression, orientation-tuned nearsurround suppression in V1 is likely generated by intra-V1 horizontal connections. These connections, at least in V1 layers 2-3, are well suited to this task, because they link preferentially neurons of similar orientation preference (Malach et al., 1993; Bosking et al., 1997) and target both excitatory and inhibitory neurons (McGuire et al., 1991). The orientation specificity of horizontal connections in other V1 layers is unknown. However, long-range connections in layers 4B and upper-4C $\alpha$ are "patchy" (Lund et al., 2003), whereas in layer 6 they are widespread and do not link domains of similar eye dominance (Li et al., 2003). Therefore, there appears to be a correlation between the sharpness of tuning of near-surround suppression across V1 laminae and the laminar location of patterned and orientation-specific horizontal connections. V1 layers with sharpest tuning of near-surround suppression also have stronger near suppression (Sceniak et al., 2001; Shushruth et al., 2009), except layer 4A, which despite strong suppression shows poor tuning. In contrast, there is no correlation between layers with sharpest orientation tuning of nearsurround suppression and layers with sharpest orientation tuning of RF responses (Ringach et al., 2002).

Broader orientation tuning of far than near-surround suppression suggests that feedback connections, the presumed substrate for far-surround suppression, are more broadly orientation biased than horizontal connections. Feedback connections to $\mathrm{V} 1$ terminate in upper and lower layers, avoiding layer 4C (Salin and Bullier, 1995), and target both excitatory and inhibitory neurons (Anderson and Martin, 2009), but their orientation organization remains controversial. Specifically, there are reports of both anatomically widespread (Rockland and Pandya, 1979; Maunsell and van Essen, 1983; Rockland, 2003) and orientationunspecific (Stettler et al., 2002) V2-to-V1 feedback connections, and patterned (Angelucci et al., 2002; Angelucci and Bressloff, 2006) and orientation-biased (Shmuel et al., 2005) feedback connections from V2 to V1 layers 2/3. The orientation organization of feedback to V1 from other extrastriate areas is unknown. It is likely that there are multiple feedback systems differing in functional specificities terminating in different V1 layers (Angelucci and Bressloff, 2006). In particular, sharper tuning of far suppression in layer $4 \mathrm{~B}$ suggests greater orientation specificity of feedback connections to this layer, while weak tuning in layers $5 / 6$ suggests orientation-unspecific feedback connections to these layers. In effect, feedback also contributes to the near surround (Fig. 1), but its effect is likely masked by the stronger tuned component of near-surround suppression. There is no correlation between the laminar distribution of the orientation tuning of far suppression and the laminar distributions of far-surround suppression strength (Shushruth et al., 2009) or RF orientation tuning (Ringach et al., 2002).

Two previous studies that examined the tuning of surround suppression, inferred two components to the underlying neural signal, one that is monocular and has very broad spatiotemporal tuning, likely originating in the LGN or input layers of V1, the other binocular and sharply tuned for orientation and spatiotemporal frequency, likely of long-range intracortical origin (Webb et al., 2005; Petrov and McKee, 2009). It is unlikely that the monocular and untuned suppression of these previous stud- 
ies corresponds to the broadly orientation-tuned far-surround suppression of our study. In our study, the far-surround stimuli activated cortical regions well beyond the spatial spread of feedforward afferents, and thus likely recruited long-range intracortical connections. The untuned, monocular, and early suppression of these previous studies is likely confined to the near surround, and was likely masked by the tuned component of near-surround suppression in our stimulus protocol.

\section{Role of near- and far-surround suppression in natural vision} The similarity of surround suppression in human and macaques suggests that this phenomenon reflects fundamental signal processing principles. A prominent hypothesis, stemming from efficient coding principles (Attneave, 1954; Barlow, 1961) and information theory (Shannon, 1948), suggests that the visual system is tuned to the statistics of natural images (Simoncelli and Olshausen, 2001; Geisler, 2008). In natural images, there is a statistical relation between edge orientation and distance between edges: nearby edges have higher probability than distant edges of being co-oriented and cocircular, and of belonging to the same physical contour (Geisler et al., 2001). The different orientation tuning of near- and far-surround suppression may reflect this statistical dependency in the visual environment. Accordingly, suppression should be narrowly orientation tuned for nearby edges, and more broadly tuned for distant edges. Such tuning would increase the coding efficiency of more frequently co-occurring contours, because the latter would evoke fewer spikes (due to tuned suppression) than less frequent contours. On the other hand, the same tuning results in increased saliency of less frequently co-occurring contours in natural images.

Perceptually, sharply orientation-tuned near-surround suppression may serve to detect small orientation differences in nearby edges, which is useful for local contour completion or figure-ground segregation (Lamme, 1995). Instead, broadly tuned far-surround suppression could serve to detect large orientation differences in distant edges, useful for perception of global contours and/or to direct saccades and/or attention to salient visual field locations that are markedly different from their surrounding (Petrov and McKee, 2006).

\section{References}

Albrecht DG, Hamilton DB (1982) Striate cortex of monkey and cat: contrast response function. J Neurophysiol 48:217-237. Medline

Alitto HJ, Usrey WM (2008) Origin and dynamics of extraclassical suppression in the lateral geniculate nucleus of the macaque monkey. Neuron 57:135-146. CrossRef Medline

Allman J, Miezin F, McGuinness E (1985) Stimulus specific responses from beyond the classical receptive field: neurophysiological mechanisms for local-global comparisons in visual neurons. Annu Rev Neurosci 8:407430. CrossRef Medline

Anderson JC, Martin KA (2009) The synaptic connections between cortical areas V1 and V2 in macaque monkey. J Neurosci 29:11283-11293. CrossRef Medline

Angelucci A, Bressloff PC (2006) The contribution of feedforward, lateral and feedback connections to the classical receptive field center and extraclassical receptive field surround of primate V1 neurons. Prog Brain Res 154:93-120. CrossRef Medline

Angelucci A, Sainsbury K (2006) Contribution of feedforward thalamic afferents and corticogeniculate feedback to the spatial summation area of macaque V1 and LGN. J Comp Neurol 498:330-351. CrossRef Medline

Angelucci A, Shushruth S (2013) Beyond the classical receptive field: surround modulation in primary visual cortex. In: The new visual neurosciences (Chalupa LM, Werner JS, eds), in press. Cambridge: MIT.

Angelucci A, Levitt JB, Walton EJ, Hupe JM, Bullier J, Lund JS (2002) Circuits for local and global signal integration in primary visual cortex. J Neurosci 22:8633-8646. Medline
Attneave F (1954) Some informational aspects of visual perception. Psychol Rev 61:183-193. CrossRef Medline

Bair W, Cavanaugh JR, Movshon JA (2003) Time course and time-distance relationships for surround suppression in Macaque V1 neurons. J Neurosci 23:7690-7701. Medline

Barlow HB (1961) Possible principles underlying the transformation of sensory messages. In: Sensory communication (Rosenblith WA, ed), pp 217 234. Cambridge: MIT.

Blakemore C, Tobin EA (1972) Lateral inhibition between orientation detectors in the cat's visual cortex. Exp Brain Res 15:439-440. Medline

Bonin V, Mante V, Carandini M (2005) The suppressive field of neurons in lateral geniculate nucleus. J Neurosci 25:10844-10856. CrossRef Medline

Bosking WH, Zhang Y, Schofield B, Fitzpatrick D (1997) Orientation selectivity and the arrangement of horizontal connections in tree shrew striate cortex. J Neurosci 17:2112-2127. Medline

Bringuier V, Chavane F, Glaeser L, Frégnac Y (1999) Horizontal propagation of visual activity in the synaptic integration field of area 17 neurons. Science 283:695-699. CrossRef Medline

Cannon MW, Fullenkamp SC (1991) Spatial interactions in apparent contrast: inhibitory effects among grating patterns of different spatial frequencies, spatial positions and orientations. Vis Res 31:1985-1998. CrossRef Medline

Cavanaugh JR, Bair W, Movshon JA (2002) Selectivity and spatial distribution of signals from the receptive field surround in macaque $\mathrm{V} 1$ neurons. J Neurophysiol 88:2547-2556. CrossRef Medline

Chen CC, Tyler CW (2002) Lateral modulation of contrast discrimination: flanker orientation effects. J Vis 2:520-530. Medline

Chubb C, Sperling G, Solomon JA (1989) Texture interactions determine perceived contrast. Proc Natl Acad Sci U S A 86:9631-9635. CrossRef Medline

DeAngelis GC, Freeman RD, Ohzawa I (1994) Length and width tuning of neurons in the cat's primary visual cortex. J Neurophysiol 71:347-374. Medline

Ejima Y, Takahashi S (1985) Apparent contrast of a sinusoidal grating in the simultaneous presence of peripheral gratings. Vision Res 25:1223-1232. CrossRef Medline

Gallant JL, Connor CE, Van Essen DC (1998) Neural activity in areas V1, V2 and V4 during free viewing of natural scenes compared to controlled viewing. Neuroreport 9:2153-2158. CrossRef Medline

Geisler WS (2008) Visual perception and the statistical properties of natural scenes. Annu Rev Psychol 59:167-192. CrossRef Medline

Geisler WS, Albrecht DG (1997) Visual cortex neurons in monkeys and cats: detection, discrimination, and identification. Vis Neurosci 14:897-919. CrossRef Medline

Geisler WS, Perry JS, Super BJ, Gallogly DP (2001) Edge co-occurrence in natural images predicts contour grouping performance. Vis Res 41:711724. CrossRef Medline

Girard P, Hupé JM, Bullier J (2001) Feedforward and feedback connections between areas V1 and V2 of the monkey have similar rapid conduction velocities. J Neurophysiol 85:1328-1331. Medline

Grinvald A, Lieke EE, Frostig RD, Hildesheim R (1994) Cortical pointspread function and long-range lateral interactions revealed by real-time optical imaging of macaque monkey primary visual cortex. J Neurosci 14:2545-2568. Medline

Hashemi-Nezhad M, Lyon DC (2012) Orientation tuning of the suppressive extraclassical surround depends on intrinsic organization of V1. Cereb Cortex 22:308-326. CrossRef Medline

Ichida JM, Schwabe L, Bressloff PC, Angelucci A (2007) Response facilitation from the "suppressive" receptive field surround of macaque V1 neurons. J Neurophysiol 98:2168-2181. CrossRef Medline

Kapadia MK, Ito M, Gilbert CD, Westheimer G (1995) Improvement in visual sensitivity by changes in local context: parallel studies in human observers and in V1 of alert monkeys. Neuron 15:843-856. CrossRef Medline

Kapadia MK, Westheimer G, Gilbert CD (1999) Dynamics of spatial summation in primary visual cortex of alert monkeys. Proc Natl Acad Sci U S A 96:12073-12078. CrossRef Medline

Lamme VA (1995) The neurophysiology of figure-ground segregation in primary visual cortex. J Neurosci 15:1605-1615. Medline

Levitt JB, Lund JS (1997) Contrast dependence of contextual effects in primate visual cortex. Nature 387:73-76. CrossRef Medline 
Levitt JB, Lund JS (2002) The spatial extent over which neurons in macaque striate cortex pool visual signals. Vis Neurosci 19:439-452. Medline

Li H, Fukuda M, Tanifuji M, Rockland KS (2003) Intrinsic collaterals of layer $6 \mathrm{Meynert}$ cells and functional columns in primate V1. Neuroscience 120:1061-1069. CrossRef Medline

Li W, Thier P, Wehrhahn C (2000) Contextual influence on orientation discrimination of humans and responses of neurons in V1 of alert monkeys. J Neurophysiol 83:941-954. Medline

Lund JS, Angelucci A, Bressloff PC (2003) Anatomical substrates for functional columns in macaque monkey primary visual cortex. Cereb Cortex 13:15-24. CrossRef Medline

Maffei L, Fiorentini A (1976) The unresponsive regions of visual cortical receptive fields. Vis Res 16:1131-1139. CrossRef Medline

Malach R, Amir Y, Harel M, Grinvald A (1993) Relationship between intrinsic connections and functional architecture revealed by optical imaging and in vivo targeted biocytin injections in primate striate cortex. Proc Natl Acad Sci U S A 90:10469-10473. CrossRef Medline

Maunsell JH, van Essen DC (1983) The connections of the middle temporal visual area (MT) and their relationship to a cortical hierarchy in the macaque monkey. J Neurosci 3:2563-2586. Medline

McGuire BA, Gilbert CD, Rivlin PK, Wiesel TN (1991) Targets of horizontal connections in macaque primary visual cortex. J Comp Neurol 305:370 392. CrossRef Medline

Mizobe K, Polat U, Pettet MW, Kasamatsu T (2001) Facilitation and suppression of single striate-cell activity by spatially discrete pattern stimuli presented beyond the receptive field. Vis Neurosci 18:377-391. CrossRef Medline

Nelson JI, Frost BJ (1978) Orientation-selective inhibition from beyond the classic visual receptive field. Brain Res 139:359-365. CrossRef Medline

Nurminen L, Kilpeläinen M, Laurinen P, Vanni S (2009) Area summation in human visual system: psychophysics, fMRI, and modeling. J Neurophysiol 102:2900-2909. CrossRef Medline

Nurminen L, Peromaa T, Laurinen P (2010) Surround suppression and facilitation in the fovea: very long-range spatial interactions in contrast perception. J Vis 10:9. CrossRef Medline

Ozeki H, Sadakane O, Akasaki T, Naito T, Shimegi S, Sato H (2004) Relationship between excitation and inhibition underlying size tuning and contextual response modulation in the cat primary visual cortex. J Neurosci 24:1428-1438. CrossRef Medline

Ozeki H, Finn IM, Schaffer ES, Miller KD, Ferster D (2009) Inhibitory stabilization of the cortical network underlies visual surround suppression. Neuron 62:578-592. CrossRef Medline

Petrov Y, McKee SP (2006) The effect of spatial configuration on surround suppression of contrast sensitivity. J Vis 6:224-238. CrossRef Medline

Petrov Y, McKee SP (2009) The time course of contrast masking reveals two distinct mechanisms of human surround suppression. J Vis 9:21.1-11. CrossRef Medline

Petrov Y, Carandini M, McKee S (2005) Two distinct mechanisms of suppression in human vision. J Neurosci 25:8704-8707. CrossRef Medline

Polat U, Sagi D (1993) Lateral interactions between spatial channels: suppression and facilitation revealed by lateral masking experiments. Vis Res 33:993-999. CrossRef Medline

Ringach DL, Shapley RM, Hawken MJ (2002) Orientation selectivity in macaque V1: diversity and laminar dependence. J Neurosci 22:5639-5651. Medline

Rockland KS (2003) Feedback connections: splitting the arrow. In: The primate visual system (Kaas JH, Collins CE, eds), pp 387-405: CRC.

Rockland KS, Pandya DN (1979) Laminar origins and terminations of cortical connections of the occcipital lobe in the Rhesus monkey. Brain Res 179:3-20. CrossRef Medline
Saarela TP, Herzog MH (2008) Time-course and surround modulation of contrast masking in human vision. J Vis 8:23.1-10. CrossRef Medline

Salin PA, Bullier J (1995) Corticocortical connections in the visual system: structure and function. Physiol Rev 75:107-154. Medline

Sceniak MP, Ringach DL, Hawken MJ, Shapley R (1999) Contrast's effect on spatial summation by macaque V1 neurons. Nat Neurosci 2:733-739. CrossRef Medline

Sceniak MP, Hawken MJ, Shapley R (2001) Visual spatial characterization of macaque V1 neurons. J Neurophysiol 85:1873-1887. Medline

Sceniak MP, Chatterjee S, Callaway EM (2006) Visual spatial summation in macaque geniculocortical afferents. J Neurophysiol 96:3474-3484. CrossRef Medline

Schwabe L, Ichida JM, Shushruth S, Mangapathy P, Angelucci A (2010) Contrast-dependence of surround suppression in macaque V1: Experimental testing of a recurrent network model. Neuroimage 52:777-792. CrossRef Medline

Sengpiel F, Sen A, Blakemore C (1997) Characteristics of surround inhibition in cat area 17. Exp Brain Res 116:216-228. CrossRef Medline

Shannon CE (1948) A mathematical theory of communication. The Bell System Technical J 27:379-423.

Shmuel A, Korman M, Sterkin A, Harel M, Ullman S, Malach R, Grinvald A (2005) Retinotopic axis specificity and selective clustering of feedback projections from V2 to V1 in the owl monkey. J Neurosci 25:2117-2131. CrossRef Medline

Shushruth S, Ichida JM, Levitt JB, Angelucci A (2009) Comparison of spatial summation properties of neurons in macaque V1 and V2. J Neurophysiol 102:2069-2083. CrossRef Medline

Shushruth S, Mangapathy P, Ichida JM, Bressloff PC, Schwabe L, Angelucci A (2012) Strong recurrent networks compute the orientation-tuning of surround modulation in primate primary visual cortex. J Neurosci 32 308-321. CrossRef Medline

Sillito AM, Grieve KL, Jones HE, Cudeiro J, Davis J (1995) Visual cortical mechanisms detecting focal orientation discontinuities. Nature 378: 492-496. CrossRef Medline

Simoncelli EP, Olshausen BA (2001) Natural image statistics and neural representation. Annu Rev Neurosci 24:1193-1216. CrossRef Medline

Snowden RJ, Hammett ST (1998) The effects of surround contrast on contrast thresholds, perceived contrast and contrast discrimination. Vision Res 38:1935-1945. CrossRef Medline

Solomon JA, Sperling G, Chubb C (1993) The lateral inhibition of perceived contrast is indifferent to on-center/off-center segregation, but specific to orientation. Vision Res 33:2671-2683. CrossRef Medline

Solomon SG, White AJ, Martin PR (2002) Extra-classical receptive field properties of parvocellular, magnocellular, and koniocellular cells in the primate lateral geniculate nucleus. J Neurosci 22:338-349. Medline

Stettler DD, Das A, Bennett J, Gilbert CD (2002) Lateral connectivity and contextual interactions in macaque primary visual cortex. Neuron 36: 739-750. CrossRef Medline

Walker GA, Ohzawa I, Freeman RD (1999) Asymmetric suppression outside the classical receptive field of the visual cortex. J Neurosci 19:10536-10553. Medline

Walker GA, Ohzawa I, Freeman RD (2000) Suppression outside the classical cortical receptive field. Vis Neurosci 17:369-379. CrossRef Medline

Webb BS, Tinsley CJ, Barraclough NE, Easton A, Parker A, Derrington AM (2002) Feedback from V1 and inhibition from beyond the classical receptive field modulates the responses of neurons in the primate lateral geniculate nucleus. Vis Neurosci 19:583-592. Medline

Webb BS, Dhruv NT, Solomon SG, Tailby C, Lennie P (2005) Early and late mechanisms of surround suppression in striate cortex of macaque. J Neurosci 25:11666-11675. CrossRef Medline 